\title{
Weak average liquid-cloud-water response to anthropogenic aerosols
}

Article

Accepted Version

Toll, V., Christensen, M., Quaas, J. and Bellouin, N. (2019) Weak average liquid-cloud-water response to anthropogenic aerosols. Nature, 572 (7767). pp. 51-55. ISSN 0028-0836 doi: https://doi.org/10.1038/s41586-019-1423-9 Available at https://centaur.reading.ac.uk/85364/

It is advisable to refer to the publisher's version if you intend to cite from the work. See Guidance on citing.

To link to this article DOI: http://dx.doi.org/10.1038/s41586-019-1423-9

Publisher: Nature Publishing Group

All outputs in CentAUR are protected by Intellectual Property Rights law, including copyright law. Copyright and IPR is retained by the creators or other copyright holders. Terms and conditions for use of this material are defined in the End User Agreement.

\section{www.reading.ac.uk/centaur}

\section{CentAUR}

Central Archive at the University of Reading

Reading's research outputs online 


\title{
Weak average liquid cloud water response to anthropogenic
}

\author{
aerosols
}

Authors: Velle Tolla,b*, Matthew Christensen ${ }^{\mathrm{a}}$, Johannes Quaas ${ }^{\mathrm{d}}$ and Nicolas Bellouin ${ }^{\mathrm{a}}$

a Department of Meteorology, University of Reading, UK

b Institute of Physics, University of Tartu, Estonia

c Atmospheric, Oceanic and Planetary Physics, University of Oxford, UK

d Institute for Meteorology, Universität Leipzig, Germany

*Corresponding author: velle.toll@ut.ee

\section{Abstract}

The cooling of the Earth's climate by anthropogenic aerosols offsets an unknown fraction of greenhouse gas warming. A potentially strong aerosol cooling effect is worrying because it implies a large sensitivity of the Earth's surface temperature to anthropogenic forcing. Aerosol-induced increases in cloud water have been postulated to lead to a substantial cooling effect. Here we provide direct observational evidence for a relatively weak average decrease in the amount of water in liquid-phase clouds. Polluted clouds downwind of various anthropogenic pollution sources, like oil refineries, smelters, coal-fired power plants, cities, wildfires, and ships, reveal cancellations between aerosol-induced cloud water increases and decreases. We estimate that the decrease in cloud water offsets $23 \%$ of the global climate cooling effect caused by aerosol-induced increases in cloud droplet number. These findings invalidate the hypothesis of a substantial climate cooling effect through cloud water increases and translate into reduced uncertainty in the projections of future climate. 


\section{Main}

Atmospheric aerosols, tiny solid and liquid particles suspended in the air, affect the climate by direct interaction with radiation and through modulation of cloud properties. Through these effects, anthropogenic aerosols cause an imbalance in the Earth's radiative budget, called radiative forcing. Aerosols mask an unknown fraction of greenhouse gas radiative forcing and thus cool the climate to an uncertain extent ${ }^{1}$. A strongly negative aerosol forcing would imply a substantial risk because it implies a large sensitivity of the Earth's surface temperature to anthropogenic radiative forcing ${ }^{2}$. A strongly negative aerosol forcing would also mean an acceleration of global warming when aerosol emissions are reduced to improve air quality ${ }^{3}$ and smaller than expected net carbon emissions compatible with specified temperature change targets, such as $+1.5^{\circ} \mathrm{C}^{4}$.

A strongly negative aerosol forcing requires large contributions from poorly-quantified aerosol impact on clouds, because the comparatively well quantified radiative forcing of aerosolradiation interactions has been estimated to offset only about $10 \%$ of the positive radiative forcing currently exerted by greenhouse gases ${ }^{1}$. There is comprehensive observational evidence for cloud brightening through the Twomey effect ${ }^{5}$, where anthropogenic aerosols lead to the formation of more numerous cloud droplets ${ }^{6-8}$. But general circulation models (GCMs) and studies based on satellite retrievals suggest that increases in cloud water content or cloud fraction are also needed for aerosol forcing more negative than about $-1.5 \mathrm{~W} / \mathrm{m}^{2}$, i.e. to offset more than half of the positive greenhouse gas forcing ${ }^{9,10}$. In this study we test the hypothesis of a substantial climate cooling effect through cloud water increases. 
The existing evidence for the sign and magnitude of the cloud liquid water path (LWP) response to increased cloud droplet concentration is limited and conflicting ${ }^{11}$. Rain can be delayed by decreased collision-coalescence efficiency of smaller cloud droplets ${ }^{12,13}$ and this can lead to increased $\mathrm{LWP}^{14}$. But process-level modelling also suggests that LWP can decrease due to aerosol-enhanced entrainment ${ }^{15-17}$ resulting from enhanced evaporation ${ }^{18}$ and decreased sedimentation $^{16}$ of smaller cloud droplets. Co-variations between LWP and aerosols in satellite data indicate both LWP increases and decreases in response to aerosol perturbations ${ }^{19,20}$. But these correlative studies are affected by cloud contamination of aerosol retrievals, aerosol swelling near clouds, wet scavenging and in-cloud aerosol processing ${ }^{21-23}$. Analyses of the relationship between cloud droplet number concentrations (CDNC) and LWP help avoid the dependence on uncertain aerosol retrievals near clouds, but rely on uncertain satellite retrievals of $\mathrm{CDNC}^{24}$. Rosenfeld et al. ${ }^{25}$ find a strongly positive relationship between CDNC and LWP. Gryspeerdt et al. ${ }^{26}$ find a non-linear relationship between CDNC and LWP, which is negative in most regions. However, such relationships do not confirm causality between LWP and CDNC changes ${ }^{26}$.

Here we overcome the limitations of correlative studies by directly comparing the properties of polluted clouds perturbed by identified aerosol sources (Fig. 1) to the properties of nearby unpolluted clouds. This method ensures that the LWP response is directly linked to the CDNC perturbation and avoids the influence of meteorological covariation between aerosols and LWP. Similar analyses of temporal and spatial anomalies in LWP caused by shipping and volcanic emissions have been previously performed for ocean regions ${ }^{27-29}$. Malavelle et al. ${ }^{28}$ found that the large volcanic eruption of Holuhraun did not result in a discernible change in LWP, but they 
could not explain why the LWP did not change. Small-scale volcano and ship tracks showed that LWP increases and decreases compensate in ocean-based low clouds to only produce a weak overall change in $\mathrm{LWP}^{27}$. But the LWP response to industrial and urban aerosols over continents, where most anthropogenic aerosol sources are located, remained unknown. We address this knowledge gap by analysing LWP responses in polluted clouds downwind of small and large cities, industries and fires (see locations in Fig. 2). Moreover, we compare LWP responses in a rich variety of clouds over land and ocean (Methods M1) and study implications of LWP changes for the effective aerosol radiative forcing.

\section{Anthropogenic pollution tracks}

Using Moderate Resolution Imaging Spectroradiometer (MODIS) satellite retrievals ${ }^{30}$, the properties of polluted low-level and mid-level liquid-phase clouds downwind of localized anthropogenic aerosol sources like smelters, oil refineries, coal-fired power stations, small industry towns and fires (Fig. 1, Methods M3) are compared to the properties of nearby unpolluted clouds (Methods M2, Extended Data Fig. 1). These quasi-linear polluted cloud features (Fig. 1) are referred to as pollution tracks. In total, about 2400 tracks have been identified in this study over 15 years of MODIS retrievals.

Anthropogenic land-based aerosol perturbations of stratiform clouds are compared to the cloud responses in ship tracks in stratocumulus clouds, and volcano tracks (Extended Data Fig. 2) in trade-wind cumulus and stratocumulus clouds ${ }^{27,29}$. Fig. 3a shows that land-based observations sample a much wider range of clouds in terms of cloud top height than ocean-based ship and volcano tracks. The occurrence of ship tracks is largely limited to clouds no higher than $1.5 \mathrm{~km}$ 
under very stable conditions. Volcano tracks occur only under a moderately wider range of conditions, in clouds up to $2.5 \mathrm{~km}$ high ${ }^{27}$. In contrast, industry and fire tracks occur in clouds up to $4.5 \mathrm{~km}$ high. In addition, the average width of ship tracks is about ten kilometres ${ }^{31}$, so ship track-like observations may not be representative of larger scale anthropogenic cloud perturbations $^{32}$. Here, tracks from large scale anthropogenic cloud perturbations caused by emissions from the megacity of Moscow and a large oil production area in Kazakhstan have been found. These larger scale cloud perturbations cover thousands of square kilometres (Fig. 1). When various types of pollution tracks are combined, the sampled meteorological conditions (Extended Data Fig. 3 and 4) cover a wide range of conditions where liquid clouds occur ${ }^{33}$ (Methods M5). Occurrence of pollution tracks in clouds for various aerosol sources in various cloud regimes provides unequivocal evidence for the existence of the Twomey effect across the globe (Fig. 2). But sampling a large variety of pollution tracks also provides the opportunity to assess the global-scale response of liquid cloud water to aerosol perturbations.

\section{LWP responses to aerosols}

Both LWP increases and decreases are observed in all types of pollution tracks (Fig. 3b), resulting in relatively weak average LWP changes (Extended Data Table 1). This means that LWP responses to aerosol perturbations are more complex than the unidirectional increases assumed from the suppression of rain $^{14}$ and observed in a limited number of pollution tracks ${ }^{34}$. The strongest average increase in LWP is observed in trade-wind cumulus clouds (Extended Data Table 1). But as radiative forcing of aerosol-cloud interactions has been observed to be dominated by perturbations to liquid stratiform clouds ${ }^{35}$, we focus on this type of cloud. 
In liquid stratiform clouds, the average change in LWP is fairly small over oceans. In ship tracks, LWP increases by $9 \%$ on average, but in volcano tracks, LWP decreases by $4 \%$ on average (Extended Data Table 1). There is a moderate decrease in LWP in land-based anthropogenic pollution tracks in stratiform clouds (Extended Data Table 1). The average decrease in LWP is $8 \%$ in industry tracks, $14 \%$ in large-scale industrial cloud perturbations and $7 \%$ in fire tracks.

\section{Meteorological control of LWP responses}

Meteorological conditions control the sign and magnitude of the LWP responses in pollution tracks (Fig. 4, Extended Data Fig. 5). Focusing on ocean and land-based warm stratiform clouds, LWP tends to decrease less, or even increase on average in lower, thinner, and precipitating clouds and in cases with moist air above clouds (Fig. 4). Conversely, LWP tends to decrease more in higher, in thicker, in non-precipitating clouds and in cases with dry air above clouds. Responses in land-based and ocean-based tracks behave similarly. But over land, pollution tracks are observed in higher and thicker clouds (Fig. 3a, Extended Data Fig. 3) so on average LWP decreases more in land-based tracks.

Our analyses of pollution tracks provide observational support for both suppression of precipitation by aerosols ${ }^{14}$ and aerosol-enhanced entrainment ${ }^{15}$. Suppression of precipitation is supported by more frequent LWP increases in precipitating clouds (Extended Data Fig. 5, Fig. 4). LWP decreases through aerosol-enhanced entrainment are supported by observed LWP decrease in case of low relative humidity above clouds (Fig. 4). But Extended Data Fig. 5 also shows large variability in the multivariate meteorological control of the LWP response in pollution tracks. Both LWP increases and decreases occur under a wide range of meteorological 
conditions (Extended Data Fig. 5). This suggests that the physical controls of the LWP response are more complex than simply a competition between aerosol-driven suppression of precipitation and enhanced entrainment. Cloud top height and thickness have the strongest impact on LWP response. The LWP response dependence on cloud height and thickness might also be explained by aerosol-enhanced entrainment because the amount of turbulent kinetic energy in the boundary layer affects aerosol-enhanced entrainment and is linked to cloud height and thickness ${ }^{36}$. But aerosol-induced changes in other boundary layer and surface processes, like changes in surface turbulent fluxes or boundary layer stability, could also lead to a dependence of the LWP response on cloud height and thickness.

\section{Radiative forcing through LWP changes}

Pollution tracks show that aerosols make clouds brighter on average, but that the average aerosol impact on cloud albedo is largely limited to the Twomey effect (Fig. 5 and 6, Extended Data Fig. 6) because adjustments due to the changes in LWP approximately cancel out. This cancellation is found across various geographical regions and cloud regimes. The average fractional decrease in cloud droplet effective radius varies between one third and more than half in the studied tracks while the average changes in LWP are only $4 \%$ to $14 \%$ (Extended Data Table 1). The relative increase in cloud albedo in ocean-based tracks is very close to the increase expected solely from the Twomey effect (Extended Data Fig. 6, Methods M4). In land-based tracks, cloud albedo increases slightly less than expected from the Twomey effect alone due to slightly stronger cloud water decreases over land on average (Extended Data Fig. 6). 
The sensitivity of LWP to CDNC perturbations from ocean and land-based tracks is used, conditioned on cloud droplet size (Methods M4), to quantify the globally-averaged relative contribution of LWP adjustments to the total radiative forcing of aerosol-cloud interactions based on pollution tracks. Variations in anthropogenic CDNC perturbations, liquid cloud coverage, cloud albedo, and solar flux are also included (Methods M4). Decreases in LWP are found to offset $23 \%$ of the global radiative forcing through the Twomey effect. The estimated global radiative forcing through the Twomey effect is $-0.52 \mathrm{~W} / \mathrm{m}^{2}$, and the corresponding radiative forcing through LWP changes is as a global average $+0.12 \mathrm{~W} / \mathrm{m}^{2}$ (Methods M4, Fig. 6). The uncertainty in CDNC perturbation since the pre-industrial period leads to an uncertainty in the estimate of total aerosol-cloud radiative forcing. But that uncertainty does not affect the weak relative contribution of LWP adjustments to that total forcing.

\section{Discussion}

The analysis of pollution tracks provides strong evidence for a relatively weak average LWP response in liquid clouds across the globe, despite the uncertainties associated with these observations. As we use relative differences between the properties of the polluted and nearby unpolluted clouds, the results are not strongly affected by the systematic biases reported for MODIS LWP retrievals ${ }^{37}$. Weak anthropogenic aerosol emissions may impact clouds without generating visible pollution tracks ${ }^{38}$, but pollution tracks universally show compensation between LWP increases and decreases under a very wide range of magnitudes of cloud perturbations (Extended Data Table 1, Extended Data Fig. 6). Consequently, it is reasonable to assume that LWP increases and decreases also compensate each other in cases where cloud perturbations are not readily visible in the satellite images. Although we sample pollution tracks 
at specific locations, a wide range of meteorological conditions where liquid clouds occur are sampled (Extended Data Fig. 4). Relatively weak global LWP response is supported by observations of both cloud water increases and decreases under wide range of meteorological conditions (Extended Data Fig. 6) and cancellations between LWP increases and decreases in various regions for various aerosol sources.

Although an influence of water vapour and heat emitted by cities and fires on the LWP response observed in city and fire tracks cannot be excluded, it is reasonable to assume that particle emissions exert the dominant influence on the cloud response, as found in ship tracks ${ }^{39}$. Aerosols absorbing solar radiation may influence cloud properties by modifying atmospheric heating rates $^{40,41}$, and such an aerosol influence is also possible in pollution tracks. Still, it is reasonable to assume that strong CDNC perturbations dominate the aerosol perturbation in pollution tracks, and regardless of forcing pathways, pollution track observations reveal a weak contribution of LWP response to anthropogenic aerosol forcing.

A possible global change in cloud fraction in response to anthropogenic aerosols could not be assessed with our approach. The $1-\mathrm{km}$ resolution of MODIS data used in this study does not allow the quantification of cloud fraction responses in pollution tracks. Observations of pollution tracks at sub-kilometre resolution could help to evaluate the cloud fraction response. Pollution tracks also leave open the possibility for aerosol-driven cloud adjustments in deep convective clouds $^{42,43}$ and ice clouds ${ }^{9}$. However, aerosol perturbations of these clouds have been assessed to most likely lead only to a small radiative forcing compared to perturbations in liquid water clouds $^{1,35,44}$. 
The universal compensation between LWP increases and decreases observed in liquid clouds downwind of very different aerosol sources under a wide range of meteorological conditions is in stark contrast with the unidirectional aerosol-induced LWP increases simulated by GCMs ${ }^{45}$. While in multiple GCMs LWP increase enhances the Twomey effect by more than $100 \%{ }^{45}$, our analysis of pollution tracks show that LWP decrease in fact offsets $23 \%$ of the Twomey effect. Cancellations between LWP increases and decreases in pollution tracks agrees with the bidirectional LWP responses found in idealised process-level model simulations ${ }^{15-17}$ and in global satellite observations of maritime clouds ${ }^{19,20}$. But the analysis of pollution tracks now shows with unprecedented confidence that the global average LWP response to anthropogenic aerosols is weak. The observational constraint on LWP response from pollution tracks brought by this study is expected to lead to improved aerosol-cloud parameterizations in GCMs and translate into a reduced uncertainty in aerosol forcing and more reliable projections of future climate. 


\section{References}

${ }^{1}$ Boucher, O. et al., Clouds and Aerosols. In: Climate Change 2013: The Physical Science Basis. Contribution of Working Group I to the Fifth Assessment Report of the Intergovernmental Panel on Climate Change [Stocker, T.F., D. Qin, G.-K. Plattner, M. Tignor, S.K. Allen, J. Boschung, A. Nauels, Y. Xia, V. Bex and P.M. Midgley (eds.)]. Cambridge University Press, Cambridge, United Kingdom and New York, NY, USA (2013).

${ }^{2}$ Stevens, B., Sherwood, S., Bony, S. \& Webb, M. Prospects for narrowing bounds on Earth's equilibrium climate sensitivity. Earth's Future 4, 512-522 (2016).

${ }^{3}$ Andreae, M., Jones, C. \& Cox, P. Strong present-day aerosol cooling implies a hot future. Nature 435, 1187-1190 (2005).

${ }^{4}$ Millar, R. et al. Emission budgets and pathways consistent with limiting warming to $1.5^{\circ} \mathrm{C}$. Nature Geoscience 10, 741-747 (2017).

${ }^{5}$ Twomey, S. Pollution and the planetary albedo. Atmospheric Environment (1967) 8, 1251-1256 (1974).

${ }^{6}$ Breon, F. Aerosol Effect on Cloud Droplet Size Monitored from Satellite. Science 295, 834-838 (2002).

${ }^{7}$ Feingold, G., Eberhard, W., Veron, D. \& Previdi, M. First measurements of the Twomey indirect effect using ground-based remote sensors. Geophysical Research Letters 30, (2003).

${ }^{8} \mathrm{McCoy}, \mathrm{D}$. et al. Natural aerosols explain seasonal and spatial patterns of Southern Ocean cloud albedo. Science Advances 1, e1500157 (2015).

${ }^{9}$ Storelvmo, T. Aerosol Effects on Climate via Mixed-Phase and Ice Clouds. Annual Review of Earth and Planetary Sciences 45, 199-222 (2017). 
${ }^{10}$ Lohmann, U. et al. Total aerosol effect: radiative forcing or radiative flux perturbation? Atmospheric Chemistry and Physics 10, 3235-3246 (2010).

${ }^{11}$ Stevens, B. \& Feingold, G. Untangling aerosol effects on clouds and precipitation in a buffered system. Nature 461, 607-613 (2009).

${ }^{12}$ Wang, M. et al. Constraining cloud lifetime effects of aerosols using A-Train satellite observations. Geophysical Research Letters 39, (2012).

${ }^{13}$ Suzuki, K., Stephens, G. \& Lebsock, M. Aerosol effect on the warm rain formation process: Satellite observations and modeling. Journal of Geophysical Research: Atmospheres 118, 170184 (2013).

${ }^{14}$ Albrecht, B. Aerosols, Cloud Microphysics, and Fractional Cloudiness. Science 245, 12271230 (1989).

${ }^{15}$ Ackerman, A., Kirkpatrick, M., Stevens, D. \& Toon, O. The impact of humidity above stratiform clouds on indirect aerosol climate forcing. Nature 432, 1014-1017 (2004).

${ }^{16}$ Bretherton, C., Blossey, P. \& Uchida, J. Cloud droplet sedimentation, entrainment efficiency, and subtropical stratocumulus albedo. Geophysical Research Letters 34, (2007).

${ }^{17}$ Wood, R. Cancellation of Aerosol Indirect Effects in Marine Stratocumulus through Cloud Thinning. Journal of the Atmospheric Sciences 64, 2657-2669 (2007).

${ }^{18}$ Small, J., Chuang, P., Feingold, G. \& Jiang, H. Can aerosol decrease cloud lifetime? Geophysical Research Letters 36, (2009).

${ }^{19}$ Chen, Y., Christensen, M., Stephens, G. \& Seinfeld, J. Satellite-based estimate of global aerosol-cloud radiative forcing by marine warm clouds. Nature Geoscience 7, 643-646 (2014).

${ }^{20}$ Lebsock, M., Stephens, G. \& Kummerow, C. Multisensor satellite observations of aerosol effects on warm clouds. Journal of Geophysical Research 113, (2008). 
${ }^{21}$ Mauger, G. \& Norris, J. Meteorological bias in satellite estimates of aerosol-cloud relationships. Geophysical Research Letters 34, (2007).

${ }^{22}$ Christensen, M. et al. Unveiling aerosol-cloud interactions - Part 1: Cloud contamination in satellite products enhances the aerosol indirect forcing estimate. Atmospheric Chemistry and Physics 17, 13151-13164 (2017).

${ }^{23}$ Neubauer, D., Christensen, M., Poulsen, C. \& Lohmann, U. Unveiling aerosol-cloud interactions - Part 2: Minimising the effects of aerosol swelling and wet scavenging in ECHAM6-HAM2 for comparison to satellite data. Atmospheric Chemistry and Physics 17, 13165-13185 (2017).

${ }^{24}$ Grosvenor, D. et al. Remote Sensing of Droplet Number Concentration in Warm Clouds: A Review of the Current State of Knowledge and Perspectives. Reviews of Geophysics 56, 409453 (2018).

${ }^{25}$ Rosenfeld, D. et al. Aerosol-driven droplet concentrations dominate coverage and water of oceanic low level clouds. Science eaav0566 (2019). doi:10.1126/science.aav0566

${ }^{26}$ Gryspeerdt, E. et al. Constraining the aerosol influence on cloud liquid water path. Atmospheric Chemistry and Physics Discussions 1-25 (2018). doi:10.5194/acp-2018-885

${ }^{27}$ Toll, V., Christensen, M., Gassó, S. \& Bellouin, N. Volcano and Ship Tracks Indicate Excessive Aerosol-Induced Cloud Water Increases in a Climate Model. Geophysical Research Letters 44, 12,492-12,500 (2017).

${ }^{28}$ Malavelle, F. et al. Strong constraints on aerosol-cloud interactions from volcanic eruptions. Nature 546, 485-491 (2017).

${ }^{29}$ Christensen, M. \& Stephens, G. Microphysical and macrophysical responses of marine stratocumulus polluted by underlying ships: 2. Impacts of haze on precipitating clouds. Journal of Geophysical Research: Atmospheres 117 (2012). 
${ }^{30}$ Platnick, S. et al. The MODIS Cloud Optical and Microphysical Products: Collection 6 Updates and Examples From Terra and Aqua. IEEE Transactions on Geoscience and Remote Sensing 55, 502-525 (2017).

${ }^{31}$ Durkee, P. et al. Composite Ship Track Characteristics. Journal of the Atmospheric Sciences $57,2542-2553$ (2000).

${ }^{32}$ Mülmenstädt, J. \& Feingold, G. The Radiative Forcing of Aerosol-Cloud Interactions in Liquid Clouds: Wrestling and Embracing Uncertainty. Current Climate Change Reports 4, 23-40 (2018).

${ }^{33}$ King, M., Platnick, S., Menzel, W., Ackerman, S. \& Hubanks, P. Spatial and Temporal Distribution of Clouds Observed by MODIS Onboard the Terra and Aqua Satellites. IEEE Transactions on Geoscience and Remote Sensing 51, 3826-3852 (2013).

${ }^{34}$ Rosenfeld, D. Suppression of Rain and Snow by Urban and Industrial Air Pollution. Science 287, 1793-1796 (2000).

${ }^{35}$ Christensen, M., Chen, Y. \& Stephens, G. Aerosol indirect effect dictated by liquid clouds. Journal of Geophysical Research: Atmospheres 121, 14,636-14,650 (2016).

${ }^{36}$ Wood, R. Stratocumulus Clouds. Monthly Weather Review 140, 2373-2423 (2012).

${ }^{37}$ Greenwald, T. A 2 year comparison of AMSR-E and MODIS cloud liquid water path observations. Geophysical Research Letters 36, (2009).

${ }^{38}$ Possner, A., Wang, H., Wood, R., Caldeira, K. \& Ackerman, T. The efficacy of aerosol-cloud radiative perturbations from near-surface emissions in deep open-cell stratocumuli. Atmospheric Chemistry and Physics 18, 17475-17488 (2018).

${ }^{39}$ Hobbs, P. et al. Emissions from Ships with respect to Their Effects on Clouds. Journal of the Atmospheric Sciences 57, 2570-2590 (2000). 
${ }^{40}$ Huang, X. et al. Effects of aerosol-radiation interaction on precipitation duringbiomass-burning season in East China. Atmospheric Chemistry and Physics 16, 10063-10082 (2016).

${ }^{41}$ Gordon, $H$. et al. Large simulated radiative effects of smoke in the south-east Atlantic. Atmospheric Chemistry and Physics 18, 15261-15289 (2018).

${ }^{42}$ Tao, W. et al. Role of atmospheric aerosol concentration on deep convective precipitation: Cloud-resolving model simulations. Journal of Geophysical Research 112, (2007).

${ }^{43}$ Yuan, T., Remer, L., Pickering, K. \& Yu, H. Observational evidence of aerosol enhancement of lightning activity and convective invigoration. Geophysical Research Letters 38 (2011).

${ }^{44}$ Penner, J., Zhou, C., Garnier, A. \& Mitchell, D. Anthropogenic Aerosol Indirect Effects in Cirrus Clouds. Journal of Geophysical Research: Atmospheres 123, 11,652-11,677 (2018).

${ }^{45}$ Ghan, S. et al. Challenges in constraining anthropogenic aerosol effects on cloud radiative forcing using present-day spatiotemporal variability. Proceedings of the National Academy of Sciences 113, 5804-5811 (2016). 


\section{Acknowledgements}

This study is funded by the University of Reading, with support from the CLouds and Aerosol Radiative Impacts and Forcing: Year 2016 (CLARIFY-2016) project, funded by the UK Natural

Environment Research Council under grant agreement NE/L013479/1. VT acknowledges support from the Estonian Research Council personal research funding grant PSG202. We thank Gunnar Myhre for comments on this work.

\section{Author contributions}

VT and NB designed the study. VT analysed the observations. MC contributed ship track observations. JQ contributed methods and input data for radiative forcing calculations. VT and NB wrote the manuscript with contributions from MC and JQ.

\section{Competing interests}

The authors declare no competing interests.

Materials \& Correspondence: correspondence and material requests should be addressed to Velle Toll (velle.toll@ut.ee).

\section{Data availability}

The MODIS cloud products MYD06_L2 from Aqua and MOD06_L2 from Terra used in this study are available from the Atmosphere Archive and Distribution System (LAADS) Distributed Active Archive Center (DAAC) https://adsweb.nascom.nasa.gov/. ERA-Interim data are 
available from European Centre for Medium-range Weather Forecasts (ECMWF) archive https://www.ecmwf.int/en/forecasts/datasets/reanalysis-datasets/era-interim. The hand-logged centre line coordinates of various types of polluted cloud tracks and their corresponding MODIS time stamps are available from University of Reading Research Data Archive https://researchdata.reading.ac.uk/208/ DOI: 10.17864/1947.208.

\section{Code availability}

Python code for detection of polluted cloud pixels in satellite images is available at GitHub https://github.com/VelleToll/polluted cloud tracks DOI: 10.5281/zenodo.2669447. 


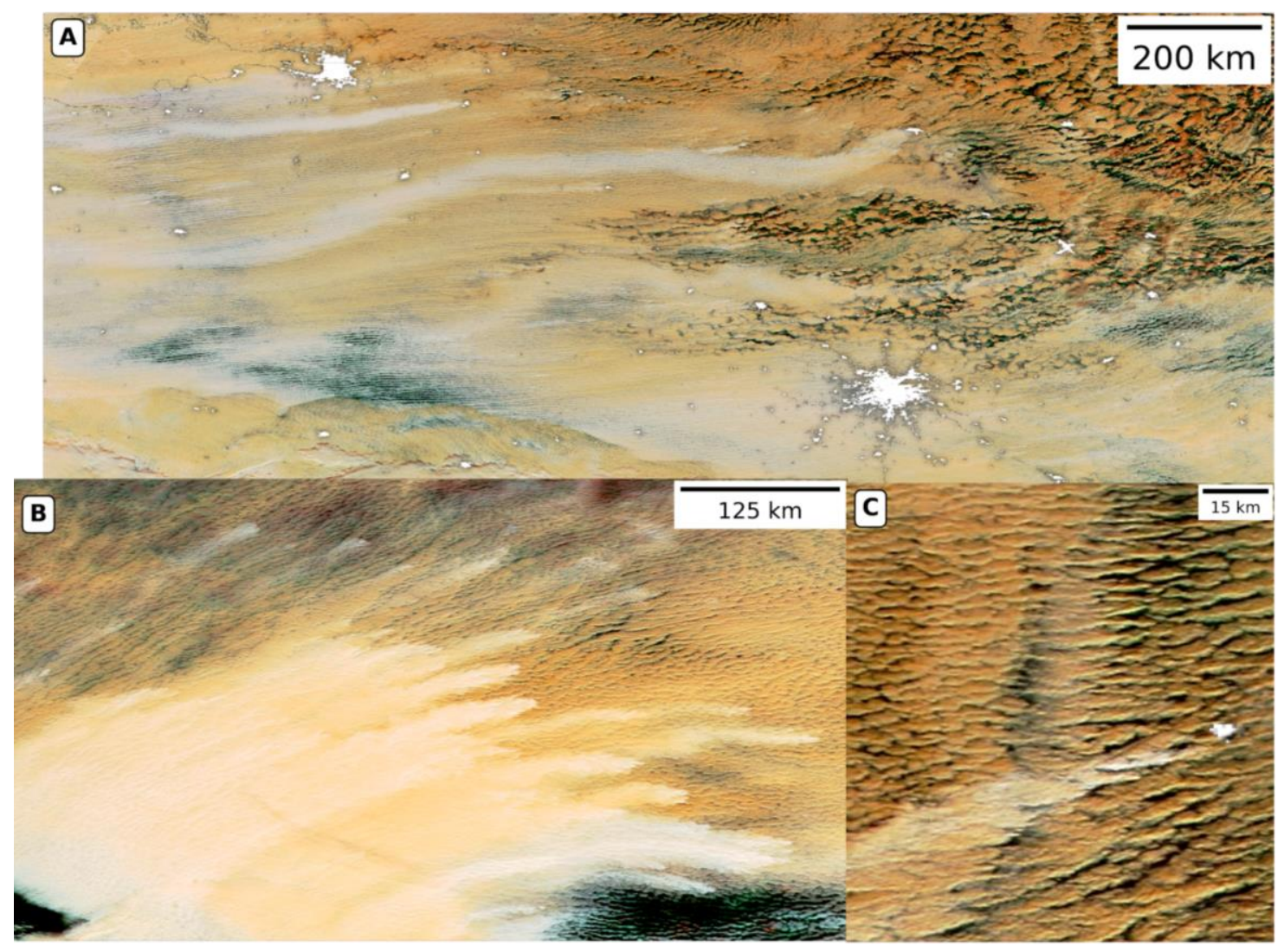

Fig. 1: Examples of pollution tracks in clouds. Moderate Resolution Imaging Spectroradiometer (MODIS) near-infrared composite daytime satellite images of pollution tracks. Polluted clouds are shown in grey-white colours and unpolluted clouds in yellow-brown colours. Note the different horizontal scales. a) Polluted clouds downwind of the megacity of Moscow and nearby cities and industries on 11-th of October 2016. Night lights of Moscow, Saint Petersburg and other smaller settlements and industries are overlain in white. b) Pollution tracks caused by fires in Siberia, Russia on 8-th of October 2016. c) Pollution track originating from nickel smelting and refining industry in Thompson, Manitoba, Canada on 19-th of October 2012. Night lights of Thompson are overlain at the origin of the track in white. 


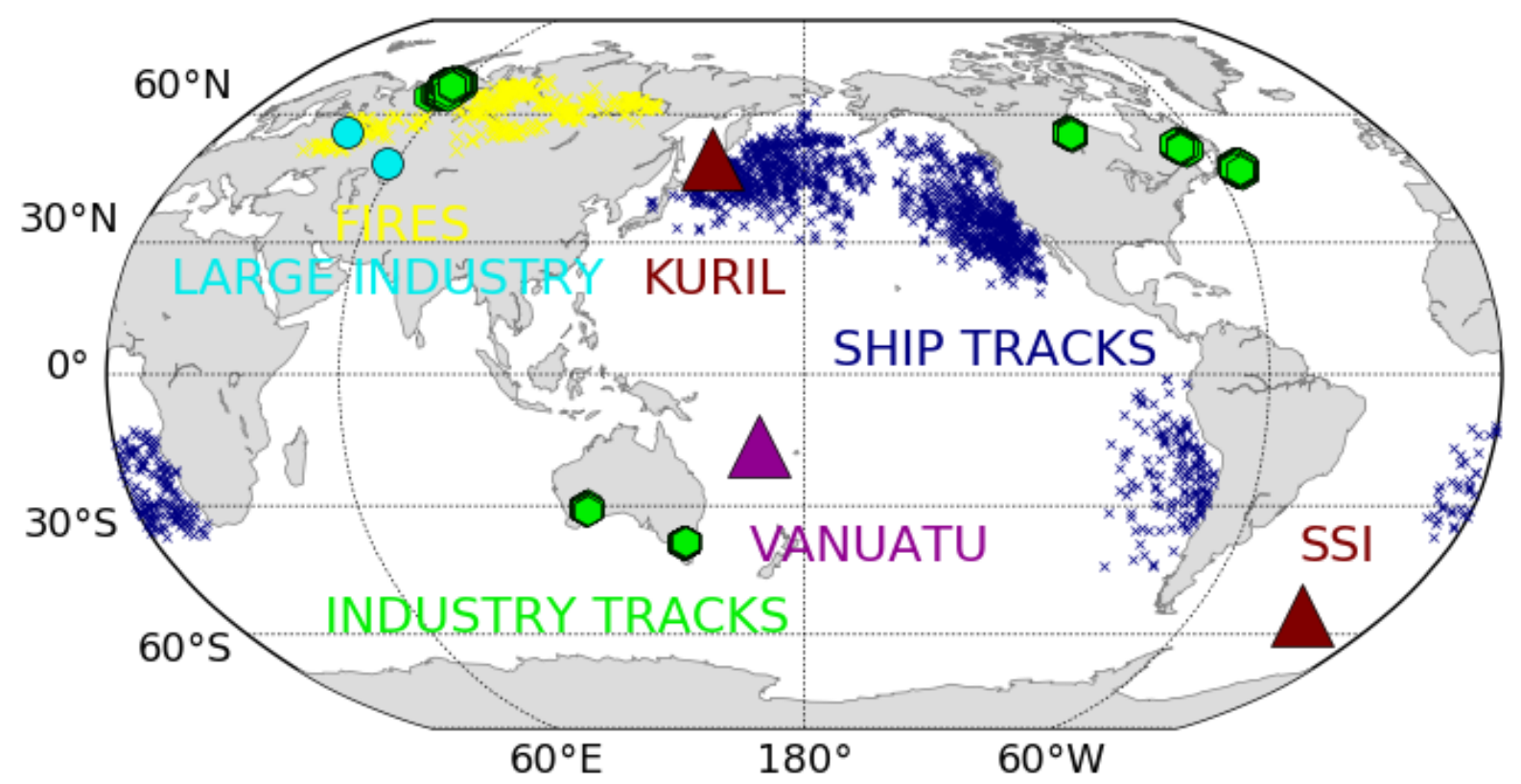

Fig. 2: Locations of analysed pollution tracks. Industry tracks, large scale industrial perturbations and fire tracks are sampled in stratiform clouds over land. Volcano tracks in stratiform clouds at Kuril and South Sandwich Islands (SSI), volcano tracks in trade-wind cumulus clouds at Vanuatu and ship tracks in stratiform clouds are sampled over ocean. The base map used in this figure originates from Python Matplotlib Basemap. 

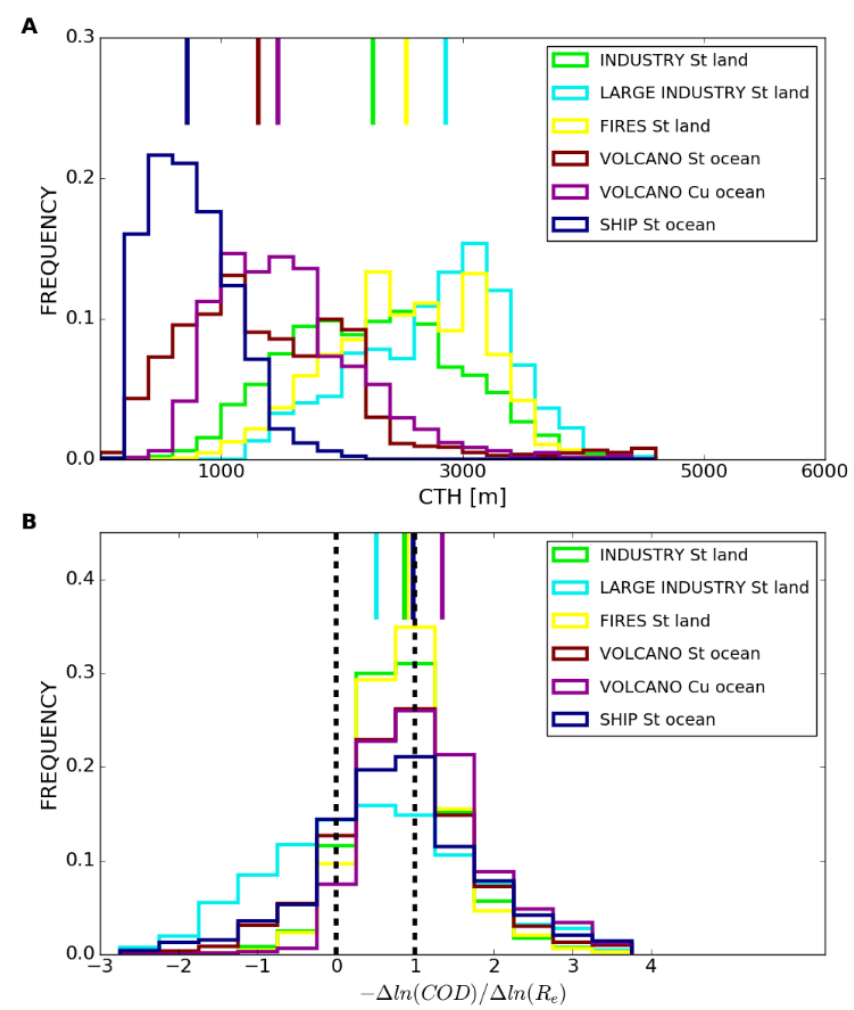

Fig. 3: Bidirectional liquid water path (LWP) responses in tracks with different heights. a)

Frequency distributions for cloud top height $(\mathrm{CTH})[\mathrm{km}]$ for various types of pollution tracks. St refers to stratiform clouds and $\mathrm{Cu}$ to trade-wind cumulus clouds. Solid vertical lines at the top of the figure represent mean CTH for various types of tracks. b) Frequency distributions comparing the changes in cloud optical depth $-\Delta \operatorname{lnCOD}$ with the changes in cloud droplet effective radius $\Delta \ln R_{\mathrm{e}}$ in various tracks. If this ratio is less (larger) than 1 , then LWP is decreased (increased) in polluted clouds. If this ratio is less (larger) than 0 , then cloud albedo is decreased (increased) in polluted clouds, since $R_{e}$ is always decreased in the polluted clouds studied. The relationship between COD, LWP and $\mathrm{R}_{\mathrm{e}}$ changes is explained under Methods M4. Only tracks with $\mathrm{R}_{\mathrm{e}}$ decrease of at least $2 \mu \mathrm{m}$ are included in the analyses. Solid vertical lines at the top of the figure represent mean ratios for various types of tracks. The vertical line for volcano St ocean is hidden behind fire and industry track lines. 


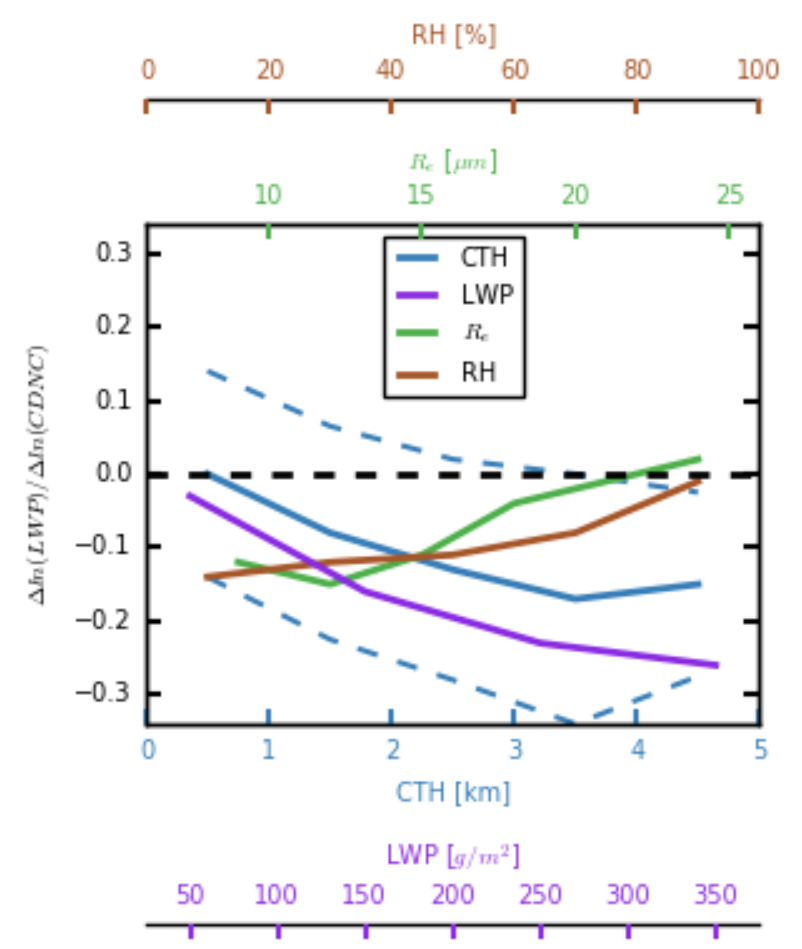

Fig. 4: Meteorological dependence of liquid water path (LWP) responses. The LWP response is normalized by cloud droplet number concentration (CDNC) perturbations in various types of pollution tracks in stratiform clouds over land and ocean (Methods M5). Average of $\Delta \operatorname{lnLWP} / \triangle \operatorname{lnCDNC}$ is calculated for each bin of the unpolluted cloud parameters. Bins are $1 \mathrm{~km}$ wide for cloud top height (CTH), $100 \mathrm{~g} / \mathrm{m}^{2}$ wide for LWP, $3 \mu \mathrm{m}$ wide for cloud droplet effective radius $\left(\mathrm{R}_{\mathrm{e}}\right)$ and $20 \%$ wide for relative humidity above cloud deck $(\mathrm{RH})$. At least 120 track observations are required for each bin. Unpolluted clouds with larger droplets are more likely precipitating. To illustrate the amount of variability within the dataset, the area between dashed blue lines covers 1 standard deviation for $\Delta \operatorname{lnLWP} / \Delta \operatorname{lnCDNC}$ dependence on $C T H$. 

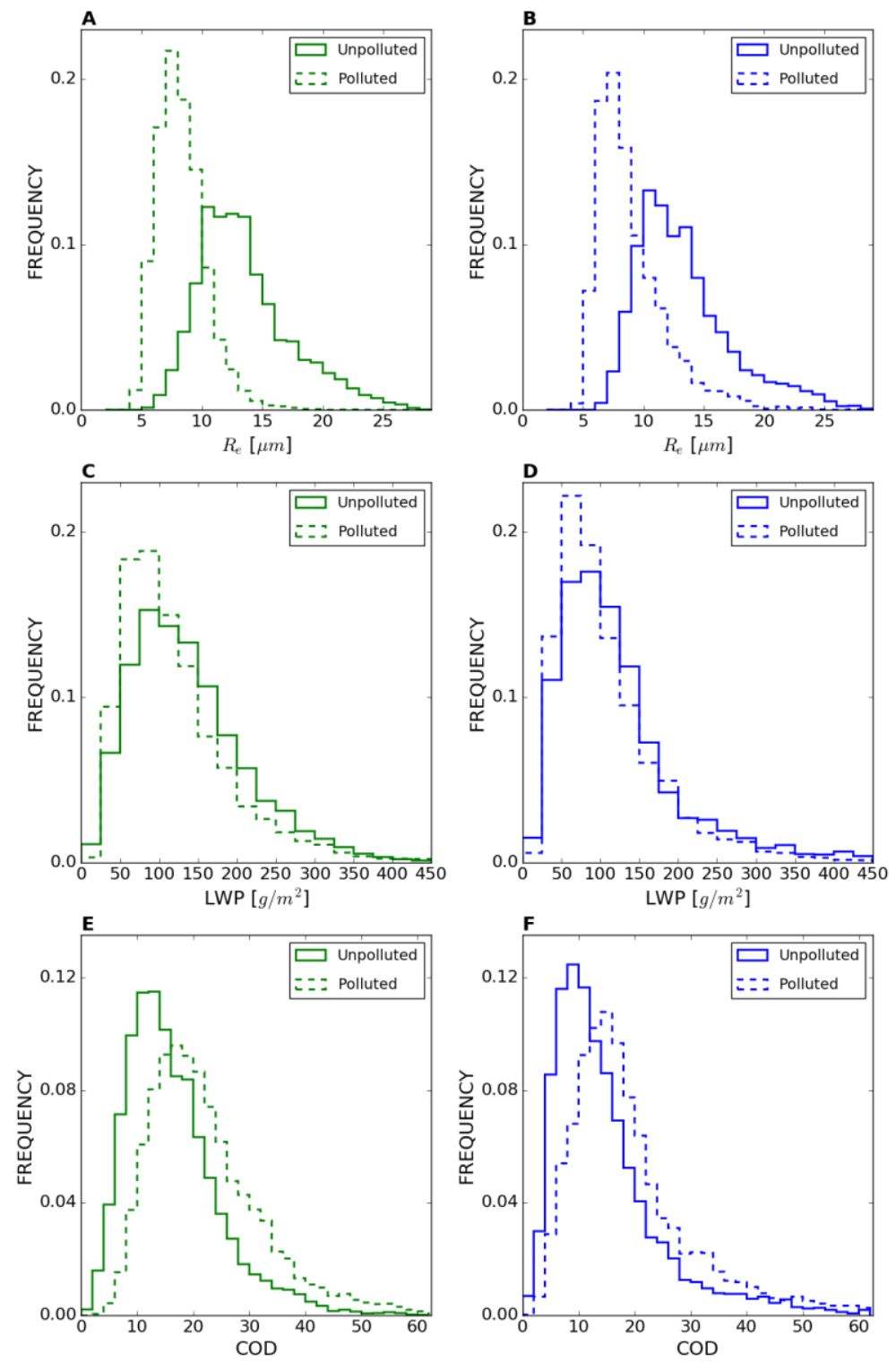

Fig. 5: Frequency distributions for polluted and unpolluted cloud properties over land and ocean. Frequency distributions for cloud droplet effective radius $\left(\mathrm{R}_{\mathrm{e}}\right)[\mu \mathrm{m}]$ over land (a) and ocean (b), liquid water path (LWP) $\left[\mathrm{g} / \mathrm{m}^{2}\right]$ over land (c) and ocean (d) and cloud optical depth (COD) over land (e) and ocean (f) for polluted and unpolluted liquid stratiform clouds. In landbased industry and fire tracks moderate decreases in LWP partly offset increase in COD through strongly decreased $\mathrm{R}_{\mathrm{e}}$. In ocean-based volcano and ship tracks LWP increases are more closely compensated by decreases. 

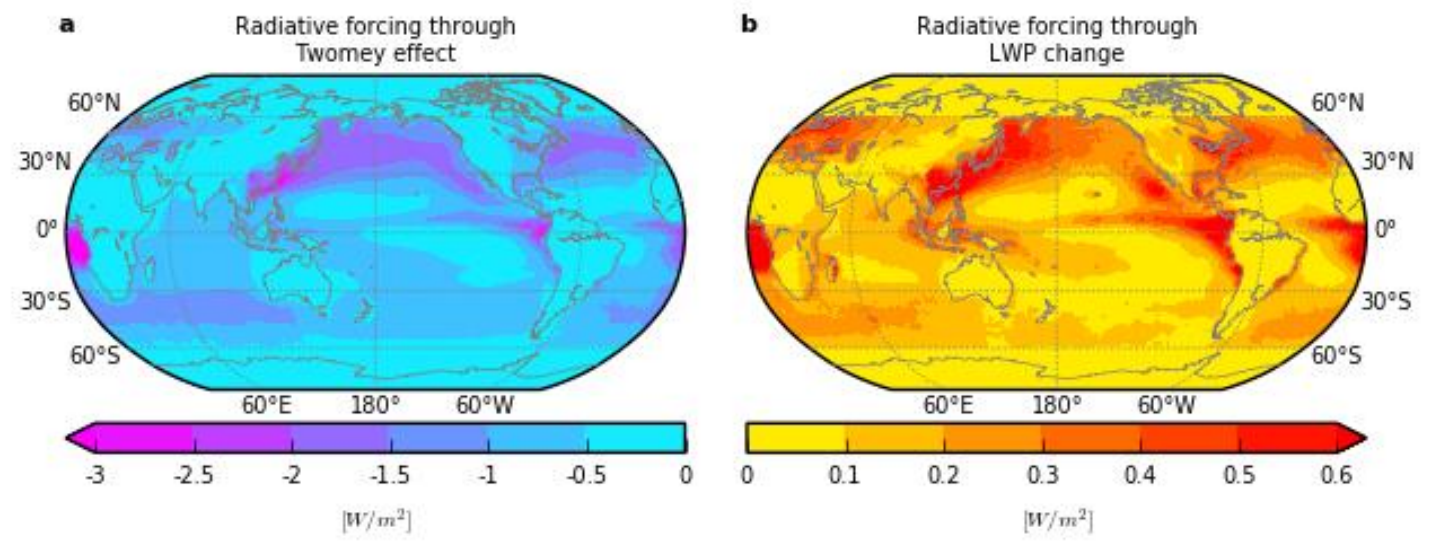

Fig. 6: Estimated radiative forcing. Radiative forcing $\left[\mathrm{W} / \mathrm{m}^{2}\right]$ through the Twomey effect (a) and LWP changes (b). The global averages are $-0.52 \mathrm{~W} / \mathrm{m}^{2}$ for the Twomey effect and $+0.12 \mathrm{~W} / \mathrm{m}^{2}$ for forcing through LWP changes. The base map used in this figure originates from Python Matplotlib Basemap. 


\section{Methods}

\section{M1. MODIS observations}

The dataset used in this study combines:

- $\quad$ An updated dataset of the ship tracks embedded in liquid-phase stratiform clouds ${ }^{27,29,46}$;

- $\quad$ The observations of volcano tracks embedded in liquid-phase stratiform clouds ${ }^{27}$;

- New observations of industry, large industrial and urban cloud perturbations and fire tracks embedded in liquid-phase stratiform clouds over land and

- $\quad$ New observations of volcano tracks embedded in liquid-phase trade-wind cumulus clouds over ocean.

Ship tracks are included only when a well-defined head at the location of ship is detected. For all other tracks, the necessary criterion for inclusion is that the emission source responsible for inducing the track is confidently identified.

Cloud properties downwind of various aerosol sources are averaged over 20-km long segments. Stratiform clouds over land are sampled by 6478 industry track segments, 984 large-scale industrial and urban cloud perturbations and 1389 fire track segments. Over ocean, cloud responses are sampled in 2521 volcano track segments in stratiform clouds, 831 volcano track segments in trade-wind cumulus clouds, and 793 ship tracks in stratiform clouds (Extended Data Table 2). The covered time period is variable for various types of tracks, but all were sampled by the same instrument (MODIS) between years 2003 to 2017.

In this work, properties of the polluted clouds are compared to the properties of the nearby unpolluted clouds using MODIS Collection 6 1-km resolution level 2 cloud products 
MYD06_L2 from Aqua and MOD06_L2 from Terra ${ }^{30}$. The 2.1- $\mu$ m near-infrared (NIR) channelbased cloud products are used to analyse aerosol-induced changes in cloud properties. Using 3.7$\mu \mathrm{m}$ channel-based products was also tested and very similar LWP responses were obtained within the uncertainty range in the products. The $2.1 \mu \mathrm{m}$ NIR signatures resulting from decreased $\mathrm{R}_{\mathrm{e}}{ }^{47}$ are used to visually identify polluted clouds in the first place. Using NIR signature (change in the $R_{e}$ ) to detect the tracks ensures that cases with either cloud thinning or thickening and cases with either decreased or increased cloud albedo in response to aerosols are included in the analyses.

NIR composite images from National Aeronautics and Space Administration (NASA) Global Imagery Browse Services are utilized for visually finding the pollution tracks (Fig. 1, Extended Data Fig. 2). These daily composite images utilize corrected reflectance from Terra MODIS bands red $=3$, green $=6$, blue $=7$. These bands correspond to wavelengths $0.459-0.479 \mu \mathrm{m}, 1.628-$ $1.652 \mu \mathrm{m}, 2.105-2.155 \mu \mathrm{m}$, respectively. Additional layers showing the locations of various industries (oil production sites, smelters, etc), MODIS and Visible Infrared Imaging Radiometer Suite (VIIRS) fire products, and images of night lights to mark locations of human activity as potential aerosol sources and locations of degassing volcanoes are utilized for locating the tracks and linking them to a specific aerosol source. In addition, the database of pollution hot spots detected from satellites ${ }^{48}$ is used to identify regions where pollution tracks are likely to occur.

The cloud response analysed in this paper rely on carefully screened MODIS data. Screening of MODIS data follows Toll et al. ${ }^{27}$. All the tracks are sampled in liquid water clouds. Only pixels with single layer (cloud multilayer flag=1) and low-level cloud top (pressure less than $500 \mathrm{hPa}$ ) 
are included. Pixels with infrared cloud phase identified as ice or mixed-phase, and ice cloud retrievals, are excluded. The track segments are included in the analyses only when the $\mathrm{R}_{\mathrm{e}}$ in polluted clouds is decreased by at least $2 \mu \mathrm{m}$ compared to the unpolluted clouds.

Volcano, industry and fire tracks are sampled at mid-latitudes and are thus associated with larger retrieval uncertainties compared to ship tracks embedded in subtropical marine stratocumulus clouds because of larger solar zenith angles at mid-latitudes ${ }^{49}$. Sampling of liquid water clouds only for volcano, industry and fire tracks minimizes the impact of larger solar zenith angles, as liquid clouds predominantly occur in warm seasons in these regions, i.e. in the period with lower solar zenith angles. Ice and mixed-phase clouds, which are more prevalent in cold seasons, i.e. in the period with higher solar zenith angles, are excluded. Toll et al. ${ }^{27}$ showed that the overall cloud responses remained the same when screening the volcano track database more strictly based on solar zenith angles (excluding cases when solar zenith angle exceeded $70^{\circ}$ ).

\section{M2. Pixel classification}

In order to compare the properties of the polluted clouds to the properties of the nearby unpolluted clouds, MODIS pixels need to be classified as polluted or unpolluted. First, pollution tracks are divided into $20-\mathrm{km}$ long segments. For the track features, a semi-automated approach $^{27,50}$ for satellite pixel classification in track segments is used, as illustrated in Extended Data Fig. 1 a). The centreline of each pollution track is manually saved by identifying the tracks visually and logging their positions using the $2.1 \mu \mathrm{m}$ NIR MODIS image. The pixels are then classified as polluted or unpolluted by applying the following across track analyses. 
At first, linear trend line given with solid blue line (Extended Data Fig. 1 a) is fitted to the NIRreflectance of pixels on track segment edges. The threshold-line given with dashed yellow line is two standard deviations above the blue line. The trend line and standard deviation are defined by the unpolluted pixels on the edges of each $20-\mathrm{km}$ long and $60-\mathrm{km}$ wide track segment. For the volcano tracks in trade-wind cumulus clouds, the segments are $100-\mathrm{km}$ wide due to different properties of the cloud field compared to stratiform clouds. NIR-reflectance of the polluted pixels is higher than threshold defined by the dashed yellow line and NIR-reflectance of the unpolluted pixels is lower than threshold defined by the dashed yellow line. The width of the area with control pixels (blue downward pointing triangles) is chosen the same as the width of the area with polluted pixels (yellow upward pointing triangles). When the polluted track is wider, the area of unpolluted control pixels on both sides of the track is also wider. Average cloud properties in polluted and unpolluted region of each segment is calculated for the data analyses. At least 20 polluted pixels and 20 unpolluted pixels on both sides of the pollution tracks are required in each segment. Polluted pixels need to have at least 3 polluted neighbouring pixels to be included.

The pixel classification method for large-scale cloud perturbations is similar to the classification method for tracks. However, an important difference is that the classification is not done across a centreline but along a line following a steep horizontal gradient in cloud properties as illustrated in Extended Data Fig. 1 b). This is because of the larger horizontal extent of the large-scale cloud perturbations compared to track features. The polluted cloud area is situated at one end of the gradient line and the unpolluted cloud area is situated at the other end of the line. First, four gradient lines for each perturbation are manually drawn on the $2.1 \mu \mathrm{m}$ NIR MODIS images. The 
4 gradient lines sample different directions: where possible, north-easterly, south-easterly, southwesterly and north-westerly. If any of these directions cover a clear-sky region, then a direction covering a cloudy region closest to the clear-sky region is sampled.

Then analyses along gradient-line is performed. Pixels from the first $20 \%$ of the line length on the side with the lower NIR-reflectance are used to define the threshold-line given with the solid blue line and dashed yellow line in Extended Data Fig. $1 \mathrm{~b}$ ). The dashed yellow line is two standard deviations above the blue solid line, where standard deviation is calculated for pixels from the first $20 \%$ of the line length. Pixels with NIR-reflectance below the dashed yellow line are unpolluted if they are situated in the first $40 \%$ of the line length on the side with lower NIRreflectance. The unpolluted pixels are given with downward pointing blue triangles in Extended Data Fig. 1 b). Pixels with NIR-reflectance above the dashed yellow line are polluted if they are situated in the last $40 \%$ of the line length on the side with higher NIR-reflectance. The polluted pixels are given with upward pointing yellow triangles. At least 100 polluted pixels and 100 unpolluted pixels are required in each perturbation area. Polluted pixels need to have at least 3 polluted neighbouring pixels to be included.

\section{M3. Sampled pollution sources}

We have detected pollution tracks on all inhabited continents in many countries. However, in the world's major industrial and urban regions of Western Europe, the Eastern United States and Eastern Asia pollution tracks are more difficult to see because of the polluted background conditions. We have preferred to sample the relatively pristine regions of Russia, Kazakhstan, Australia and Canada instead of the major urban and industrial regions to benefit from stronger 
contrasts in cloud properties that ensure that we are indeed looking at an anthropogenic cloud perturbation. In fact, in otherwise relatively clean background cloud deck, polluted cloud tracks can be used to detect localized pollution sources. Subvisible pollution tracks in more polluted regions are unlikely to behave differently from those sampled in pristine regions, as we have detected similar LWP response behaviour across a wide range of cloud perturbations (Extended Data Tables 1 and 3, Extended Data Fig. 6).

Fig. 2 shows the locations of the sampled tracks. Most emission sources in the dataset are strong sources of sulphur dioxide $\left(\mathrm{SO}_{2}\right)$, from which sulphate aerosols are formed and then act as cloud condensation nuclei. Volcano tracks in stratiform clouds are sampled at South Sandwich Islands and Kuril Islands volcanoes. Volcano tracks in trade-wind cumulus clouds are sampled at Ambrym volcano of Vanuatu. Industry tracks are sampled from Canada, Russia and Australia. Pollution tracks in Canada come from nickel smelting and refining industries in Thompson, Manitoba, an iron ore facility in Labrador City, Newfoundland and Labrador, and the North Atlantic Refining crude oil refinery near Arnold's Cove, Newfoundland and Labrador. Pollution tracks in Russia are sampled at oil refineries in Nenets region, Russia, situated south of Novaya Zemlya in the Timan-Pechora Basin. Pollution tracks in Australia are sampled at the brown coalfired thermal Loy Yang power station in Tralargon, Victoria, and at the Super Pit gold mine and smelting facilities in Kalgoorlie-Boulder, east-northeast of Perth. Large-scale industrial and urban cloud perturbations originate from the city of Moscow in Russia and the Kazakhoyl Alibekmola oil production facilities in western Kazakhstan south of Saga in the Aktobe region. Moscow emissions come from the transport and domestic sectors, and metallurgy, machinery and chemical industries. 
Expected emissions rates of $\mathrm{SO}_{2}$ are very different between the studied emission sources (Extended Data Table 3). Volcanoes emit more than 1000 times more than ships, with emission of $\mathrm{SO}_{2}$ from Ambrym volcano exceeding $1000 \mathrm{kt} / \mathrm{year}^{51}$ while $\mathrm{SO}_{2}$ emission rates from ships are below $1 \mathrm{kt} / \mathrm{year}^{39}$. The $\mathrm{SO}_{2}$ emission rates from localized industries like smelters, oil refineries and power plants lie between emission rates from ships and volcanoes ${ }^{48}$.

\section{M4. Radiative forcing}

We estimate the relative importance of CDNC and LWP changes for aerosol effective radiative forcing through aerosol-cloud interactions using sensitivity of LWP to CDNC from pollution tracks. We calculate radiative forcing through the Twomey effect and LWP changes (Fig. 6) using equation $1^{52}$. We assume here that the effective radiative forcing through aerosol-cloud interactions is sum of the forcing through Twomey effect and forcing through LWP changes:

$\Delta \mathrm{SW}_{\mathrm{TOA}}=-\mathrm{SW}_{\text {downwelling }} * \mathrm{CF}_{\text {liquid }} * \mathrm{~A}_{\text {liquid }} *\left(1-\mathrm{A}_{\text {liquid }}\right) *\left(5 / 6 \operatorname{lnLWP} \mathrm{P}_{\text {tracks }} / \Delta \ln \mathrm{CDNC}_{\text {tracks }}+1 / 3\right) * \Delta \ln C D N C_{\text {global }}(1)$,

where $\Delta \mathrm{SW}_{\text {TOA }}$ is the calculated change in backscattered shortwave (SW) flux at the top of the atmosphere (TOA), i.e. the aerosol indirect radiative forcing $\left[\mathrm{W} / \mathrm{m}^{2}\right] . \mathrm{SW}_{\text {downwelling }}$ is the downwelling SW flux at the cloud top $\left[\mathrm{W} / \mathrm{m}^{2}\right]$. Clouds and the Earth's Radiant Energy System $(\mathrm{CERES})^{53}$ clear-sky downwelling SW fluxes at the surface are used to approximate the SW flux at the cloud top to account for the attenuation of SW radiation in the clear-sky atmosphere. Real cloud top SW flux would be larger than clear-sky downwelling SW flux at the surface, meaning our forcing estimate is conservative. $\mathrm{CF}_{\text {liquid }}$ is the liquid cloud fraction from MODIS. A $\mathrm{A}_{\text {liquid }}$ is the broadband SW liquid cloud albedo estimated from CERES:

$\mathrm{A}_{\text {liquid }}=\left(\mathrm{A}_{\text {allsky }}-\left(1-\mathrm{CF}_{\text {total }}\right) * \mathrm{~A}_{\text {clearsky }}\right) / \mathrm{CF}_{\text {total }}(2)$, 
where $\mathrm{A}_{\text {allsky }}$ is the broadband $\mathrm{SW}$ all-sky albedo, $\mathrm{CF}_{\text {total }}$ is the total cloud fraction and $\mathrm{A}_{\text {clearsky }}$ is the broadband SW clear-sky albedo.

To calculate the contribution of LWP adjustments to aerosol-cloud radiative forcing, $\Delta \operatorname{lnLWP} P_{\text {tracks }} / \Delta \operatorname{lnCDNC}_{\text {tracks }}$ relationships are conditioned on the cloud droplet effective radius (Extended Data Table 4). The droplet size is a proxy for the relevant LWP adjustment effects: if droplets are large, the precipitation sink may be large; if they are small, the evaporation sink may be more prevalent. One relationship for $\Delta \operatorname{lnLWP}$ tracks $/ \Delta \operatorname{lnCDNC}_{\text {tracks }}$ is derived from industry and fire tracks and used over land and a second relationship is derived from volcano tracks and ship tracks and used over ocean. For each grid box, the $\Delta \operatorname{lnLWP} P_{\text {tracks }} / \Delta \operatorname{lnCDNC} C_{\text {tracks }}$ value is chosen based on the monthly-averaged MODIS cloud droplet size. Standard errors, calculated as standard deviation divided by the square root of the sample size, are provided for the mean $\Delta \operatorname{lnLWP} P_{\text {tracks }} / \Delta \operatorname{lnCDNC} C_{\text {tracks }}$ values given in Extended Data Tables 2 and 4.

To calculate solely the Twomey effect, $\Delta \operatorname{lnLWP} P_{\text {tracks }} / \Delta \operatorname{lnCDNC} C_{\text {tracks }}=0$. We calculate the relative change in $\mathrm{CDNC}$ in pollution tracks compared to the nearby unpolluted clouds ${ }^{27,54,55}$ (i.e. $\Delta \operatorname{lnCDNC} \mathrm{C}_{\text {tracks }}$ ) assuming that

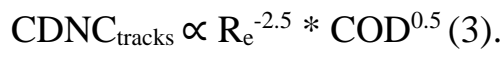

$\triangle \operatorname{lnCDNC} \mathrm{Clobal}_{\text {is }}$ the global CDNC perturbation estimated from the anthropogenic aerosol optical depth perturbation $\triangle \ln \mathrm{AOD}_{\mathrm{MACC}}$ taken from the MACC reanalysis ${ }^{56}$ and from the susceptibility of $\mathrm{CDNC}$ to $\mathrm{AOD}$ changes $\left(\Delta \operatorname{lnCDNC} \mathrm{global}_{\mathrm{g}} / \mathrm{ln}_{\mathrm{n}} \mathrm{AOD}_{\text {global }}\right)$ taken from MODIS satellite data ${ }^{52}$ : $\Delta \operatorname{lnCDNC} C_{\text {global }}=\Delta \operatorname{lnCDNC} C_{\text {global }} / \Delta \ln \mathrm{AOD}_{\text {global }} * \Delta \ln \mathrm{AOD}_{\mathrm{MACC}}(4)$.

The global spatial distribution of radiative forcing is calculated using monthly distributions, except for $\Delta \operatorname{lnCDNC} \mathrm{global}_{\mathrm{gl}} / \Delta \ln \mathrm{AOD}_{\text {global }}$ where seasonal distributions are used $^{52}$. 
In Extended Data Fig. 6, the cloud albedo, A, in pollution tracks is calculated from MODIS LWP, Re and solar zenith angle using the BUGSrad two-stream radiative transfer code ${ }^{57}$. Six SW bands are used to calculate cloud albedo. The cloud albedo susceptibility ${ }^{58,59}$ in pollution tracks is compared to the susceptibility expected just from the Twomey effect that assumes a constant LWP (Extended Data Fig. 6):

$\Delta \mathrm{A} /[\mathrm{A}(1-\mathrm{A})]=1 / 3 \Delta \ln \mathrm{CDNC}(5)$.

The relative magnitudes of the $R_{e}$ decreases are compared with the relative magnitude of LWP changes in Extended Data Table 1. The net fractional change in cloud albedo (A) is approximately proportional to the fractional change in COD, given by equation $6^{60}$. We compare the relative contributions of fractional LWP and $\mathrm{R}_{\mathrm{e}}$ changes to COD and cloud albedo changes: $\Delta \mathrm{COD} / \mathrm{COD}=\Delta \mathrm{LWP} / \mathrm{LWP}-\Delta \mathrm{R}_{\mathrm{e}} / \mathrm{R}_{\mathrm{e}} \propto \Delta \mathrm{A} / \mathrm{A}(6)$.

This is an approximate comparison and the average changes in LWP and $\mathrm{R}_{\mathrm{e}}$ do not strictly add up to the change in COD (Extended Data Table 1), but it is still very clear that the LWP response is much smaller compared to $\mathrm{R}_{\mathrm{e}}$ changes in various types of tracks. The residual in the comparison of relative LWP and $\mathrm{R}_{\mathrm{e}}$ change contributions to COD changes might be caused by the impact of the 3 -dimensional cloud structure on the retrieval of cloud optical properties ${ }^{60}$. Fig. $3 \mathrm{~b}$ compares the magnitude of the decrease in cloud droplet size $\Delta \ln R e$ to the total change in cloud optical depth $-\Delta \operatorname{lnCOD}$.

\section{M5. Meteorological conditions}

We analyse cloud responses in anthropogenic land-based aerosol perturbations of stratiform clouds and the cloud responses in ship tracks in stratocumulus clouds, as well as volcano tracks 
in trade-wind cumulus and stratocumulus clouds (Fig. 2). The distinction between stratiform and cumulus clouds is based on visual inspection of satellite images, the cumulus clouds being sampled in broken cloud fields. The frequency distributions for LWP, $R_{e}$ and COD in the pollution tracks embedded in liquid-water clouds (Fig. 5 and Extended Data Fig. 3) cover the range of variations in these properties observed in MODIS data globally ${ }^{33}$. Ocean-based ship and volcano tracks are sampled mostly in clouds lower than $2.5 \mathrm{~km}$ (Fig. 3a). But sampling landbased tracks helps to cover the range of global variations of the joint COD - cloud height histogram of liquid water clouds (Extended Data Fig. 4) ) $^{33}$. Conditions under which ship tracks are sampled are also special because of very high lower-tropospheric stability values (Extended Data Fig. 3) and low relative humidities above clouds (Extended Data Fig. 3), as these conditions are characteristic of sub-tropical stratocoumulus regions ${ }^{29}$ where ship tracks are most frequently observed. Volcano tracks over ocean and land-based pollution tracks sample much wider range of values for lower tropospheric stability and relative humidities above clouds (Extended Data Fig. 3).

To study the dependence of LWP response on meteorological conditions, MODIS retrievals ${ }^{30}$ are used together with ERA-Interim reanalysis data ${ }^{61}$. Cloud top height, LWP and $\mathrm{R}_{\mathrm{e}}$ of the unpolluted clouds are taken from MODIS. When cloud droplets in the unpolluted clouds are larger than $14 \mu \mathrm{m}$, then clouds are likely precipitating ${ }^{62}$. Cloud-Aerosol Lidar and Infrared Pathfinder Satellite Observations (CALIPSO) cloud top height ${ }^{63}$ is used for ship tracks. Abovecloud relative humidity comes from ERA-Interim. To derive above-cloud relative humidity, 6hourly data at $0.75^{\circ} \mathrm{X} 0.75^{\circ}$ horizontal resolution and at $25 \mathrm{hPa}$ vertical resolution is used. 
Relative humidity above the height defined by cloud top pressure is used for land-based tracks.

For volcano and ship tracks, relative humidity above the temperature inversion is used ${ }^{27}$. 


\section{Methods References}

${ }^{46} \mathrm{Chen}, \mathrm{Y}$. et al. Occurrence of lower cloud albedo in ship tracks. Atmospheric Chemistry and Physics 12, 8223-8235 (2012).

${ }^{47}$ Coakley, J., Bernstein, R. \& Durkee, P. Effect of Ship-Stack Effluents on Cloud Reflectivity. Science 237, 1020-1022 (1987).

${ }^{48}$ Fioletov, V. E. et al. A global catalogue of large $\mathrm{SO} 2$ sources and emissions derived from the Ozone Monitoring Instrument. Atmospheric Chemistry and Physics 16 (18), 11497 (2016).

${ }^{49}$ Grosvenor, D. \& Wood, R. The effect of solar zenith angle on MODIS cloud optical and microphysical retrievals within marine liquid water clouds. Atmospheric Chemistry and Physics 14, 7291-7321 (2014).

${ }^{50}$ Segrin, M., Coakley, J. \& Tahnk, W. MODIS Observations of Ship Tracks in Summertime Stratus off the West Coast of the United States. Journal of the Atmospheric Sciences 64, 43304345 (2007).

${ }^{51}$ Carn, S., Fioletov, V., McLinden, C., Li, C. \& Krotkov, N. A decade of global volcanic SO2 emissions measured from space. Scientific Reports 7, (2017).

${ }^{52}$ Quaas, J., Boucher, O., Bellouin, N. \& Kinne, S. Satellite-based estimate of the direct and indirect aerosol climate forcing. Journal of Geophysical Research: Atmospheres 113 (2008).

${ }^{53}$ Kato, S. et al. Surface Irradiances Consistent with CERES-Derived Top-of-Atmosphere Shortwave and Longwave Irradiances. Journal of Climate 26, 2719-2740 (2013).

${ }^{54}$ Brenguier, J. et al. Radiative Properties of Boundary Layer Clouds: Droplet Effective Radius versus Number Concentration. Journal of the Atmospheric Sciences 57, 803-821 (2000).

${ }^{55}$ Quaas, J., Boucher, O. \& Lohmann, U. Constraining the total aerosol indirect effect in the LMDZ and ECHAM4 GCMs using MODIS satellite data. Atmospheric Chemistry and Physics 6, 947-955 (2006). 
${ }^{56}$ Bellouin, N., Quaas, J., Morcrette, J. \& Boucher, O. Estimates of aerosol radiative forcing from the MACC re-analysis. Atmospheric Chemistry and Physics 13, 2045-2062 (2013).

${ }^{57}$ Stephens, G., Gabriel, P. \& Partain, P. Parameterization of Atmospheric Radiative Transfer. Part I: Validity of Simple Models. Journal of the Atmospheric Sciences 58, 3391-3409 (2001).

${ }^{58}$ Ackerman, A. et al. Effects of Aerosols on Cloud Albedo: Evaluation of Twomey's Parameterization of Cloud Susceptibility Using Measurements of Ship Tracks. Journal of the Atmospheric Sciences 57, 2684-2695 (2000).

${ }^{59}$ Platnick, S. \& Twomey, S. Determining the Susceptibility of Cloud Albedo to Changes in Droplet Concentration with the Advanced Very High Resolution Radiometer. Journal of Applied Meteorology 33, 334-347 (1994).

${ }^{60}$ Christensen, M. \& Stephens, G. Microphysical and macrophysical responses of marine stratocumulus polluted by underlying ships: Evidence of cloud deepening. Journal of Geophysical Research 116, (2011).

${ }^{61}$ Dee, D. et al. The ERA-Interim reanalysis: configuration and performance of the data assimilation system. Quarterly Journal of the Royal Meteorological Society 137, 553-597 (2011).

${ }^{62}$ Rosenfeld, D., Wang, H. \& Rasch, P. The roles of cloud drop effective radius and LWP in determining rain properties in marine stratocumulus. Geophysical Research Letters 39 (2012).

${ }^{63}$ Winker, D. et al. The CALIPSO Mission: A global 3D view of aerosols and clouds. Bulletin of the American Meteorological Society 91, 1211-1230 (2010). 


\section{Extended data figure legends and extended data table titles}

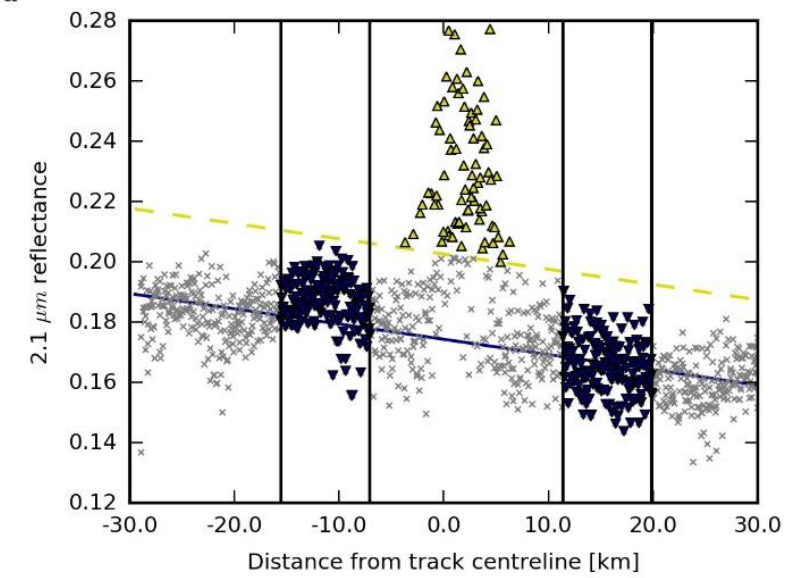

b

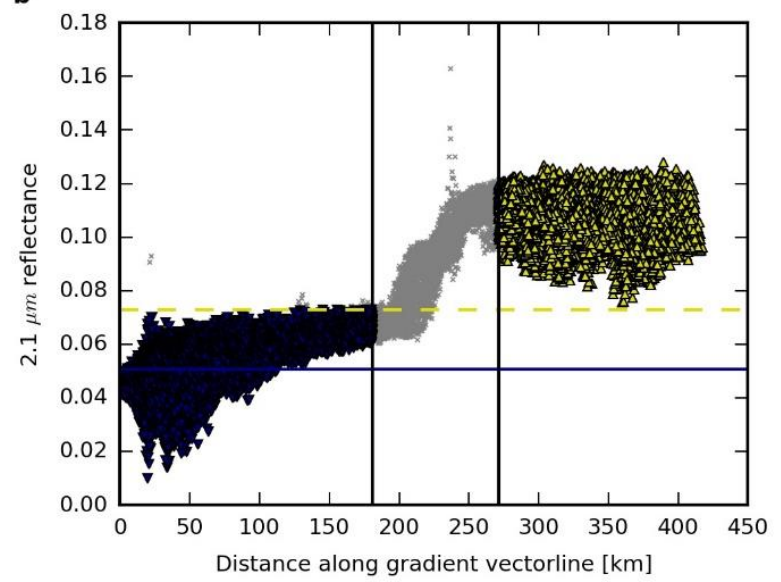

Extended Data Fig. 1: Classification of MODIS cloud pixels as polluted or unpolluted. Both in pollution tracks and in case of larger scale industrial perturbations, polluted pixels are defined by their higher near-infrared (NIR) reflectance compared to the nearby unpolluted clouds. Polluted pixels are shown as yellow upward pointing triangles and unpolluted control pixels are shown as blue downward pointing triangles. The pixels represented by grey crosses are not included in the analyses. The pixel classification for tracks (a) and for large scale cloud perturbations (b) is illustrated. 
a
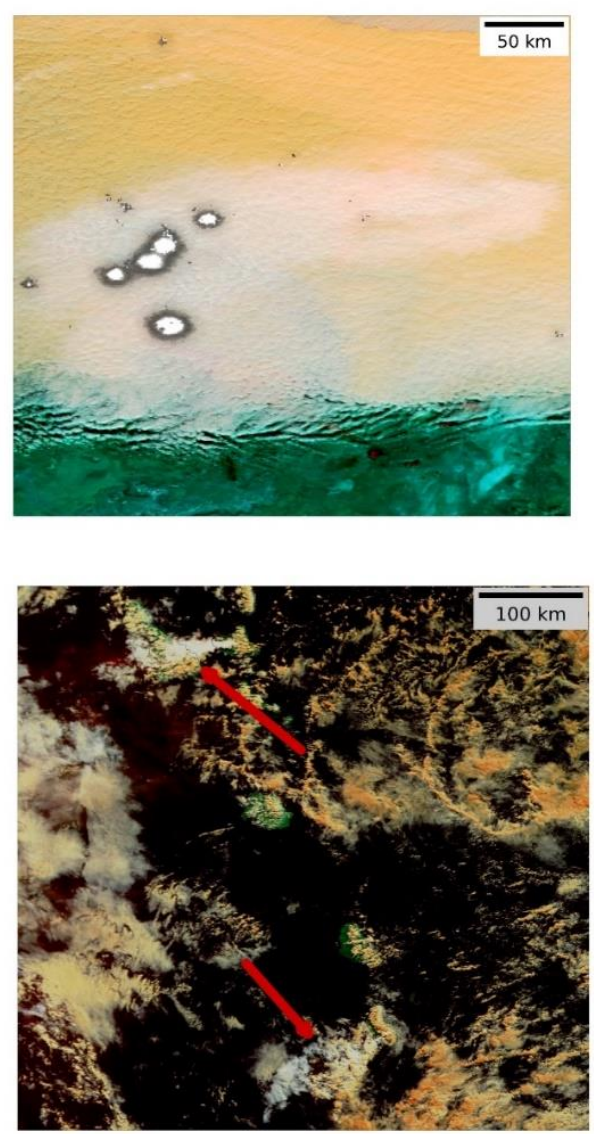

b

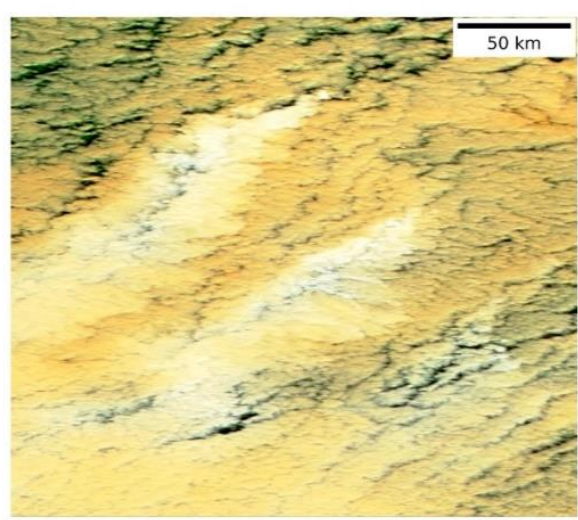

d

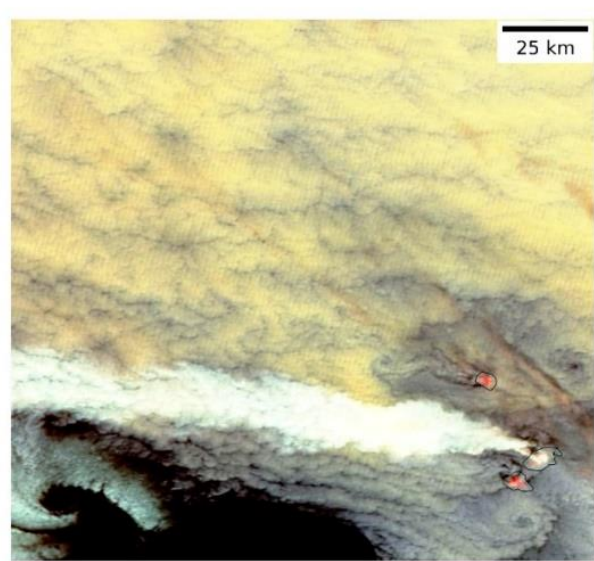

Extended Data Fig. 2: Further examples of pollution tracks. Brighter polluted clouds in greyish-whitish colours are distinguishable from nearby unpolluted clouds given in yellowishbrownish colours. Note the different map scales in images. a) Industrial cloud perturbation caused by oil production in Kazakhstan on 20-th of November 2012. Night lights of oil production industry are given in white colour. b) Pollution tracks originating from oil refining industry in Nenets region, Russia on 8-th of August 2006. c) Two volcano tracks in trade-wind cumulus clouds at Vanuatu Island volcanoes on 6-th of July 2016. The red arrows point towards volcano tracks. d) A volcano track in stratiform clouds at Kuril Islands volcano on 23-th of April 2016. 

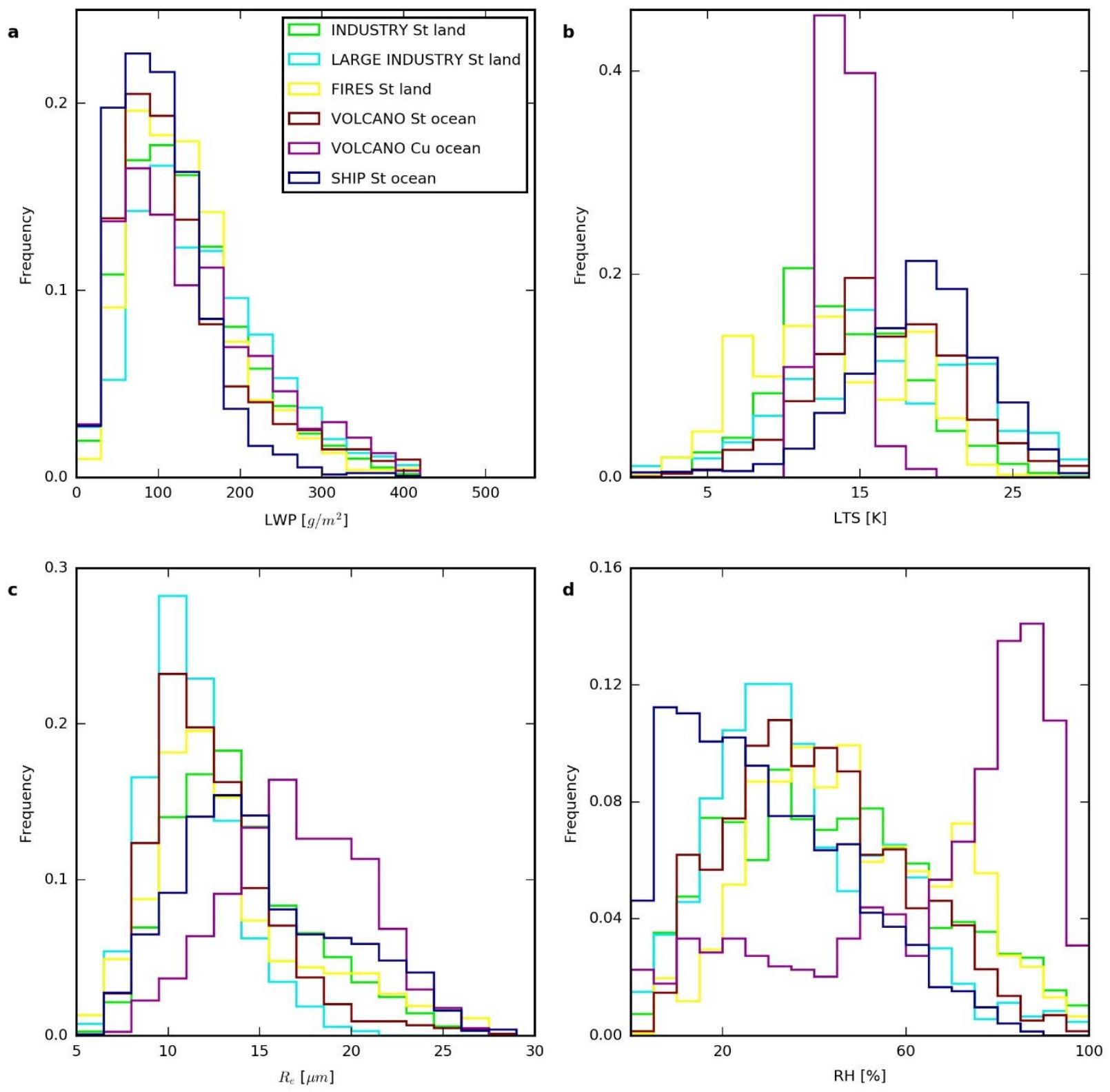

Extended Data Fig. 3: Meteorological conditions in various types of tracks. Frequency distributions for a) liquid water path (LWP) $\left[\mathrm{g} / \mathrm{m}^{2}\right]$, b) lower tropospheric stability (LTS) $[\mathrm{K}], \mathbf{c}$ ) cloud droplet effective radius $\left(\mathrm{R}_{\mathrm{e}}\right)[\mu \mathrm{m}]$ and $\mathbf{d}$ ) above cloud relative humidity ( $\left.\mathrm{RH}\right)$ [\%] for unpolluted clouds adjacent to various types of pollution tracks. Pollution tracks are sampled under wide range of meteorological conditions. St refers to stratiform clouds and $\mathrm{Cu}$ to tradewind cumulus clouds. 
a

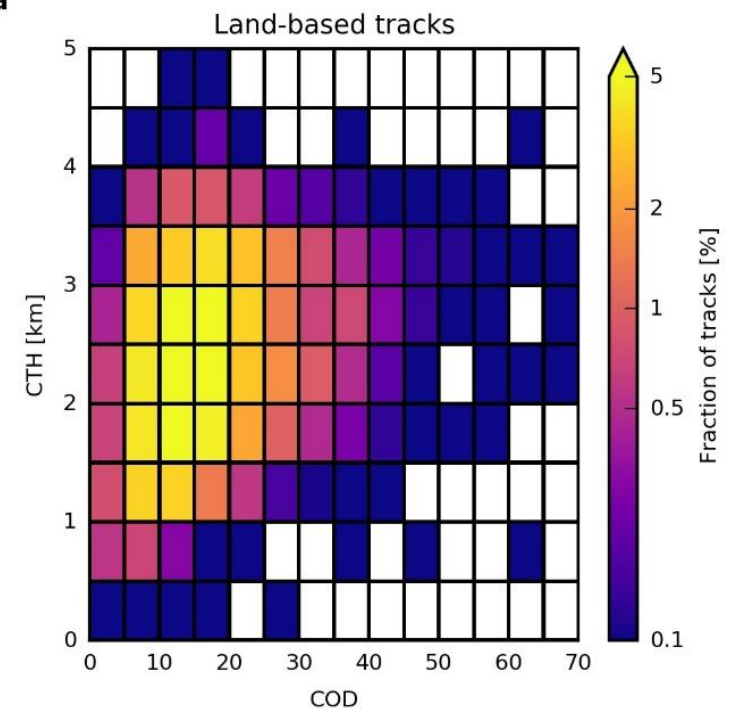

b

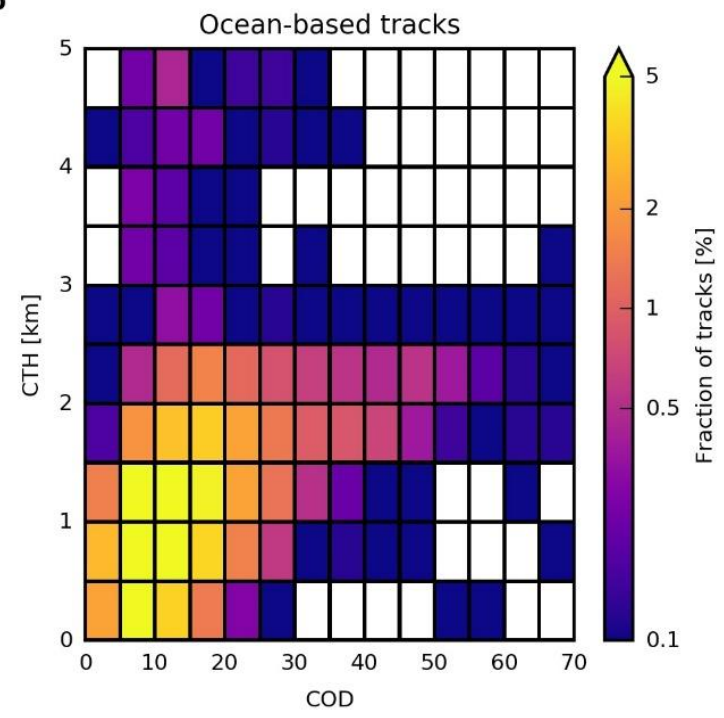

Extended Data Fig. 4: Meteorological conditions sampled over land and ocean. Joint histogram for cloud top height $(\mathrm{CTH})[\mathrm{km}]$ and cloud optical depth (COD) in unpolluted clouds adjacent to the land-based (a) and ocean-based (b) pollution tracks embedded in stratiform clouds. Note the non-linear colour scales. 

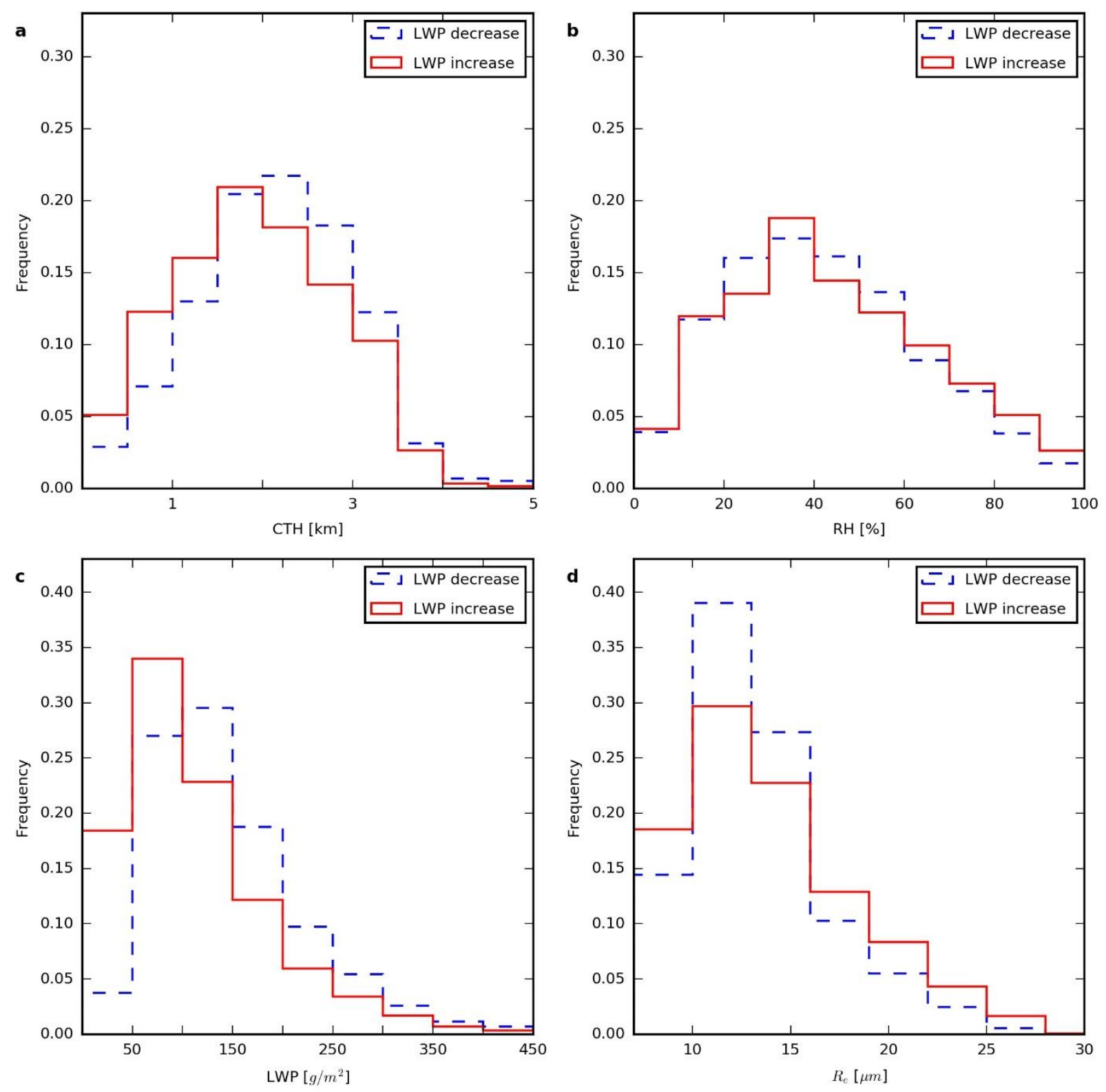

Extended Data Fig. 5: Frequency distributions of liquid water path (LWP) increases and decreases depending on the unpolluted cloud properties. Frequency distribution of LWP increases and decreases depending on a) cloud top height $(\mathrm{CTH})[\mathrm{km}]$, b) relative humidity above clouds (RH) [\%], c) liquid water path (LWP) $\left[\mathrm{g} / \mathrm{m}^{2}\right]$ and d) cloud droplet effective radius $\left(\mathrm{R}_{\mathrm{e}}\right)[\mu \mathrm{m}]$. 

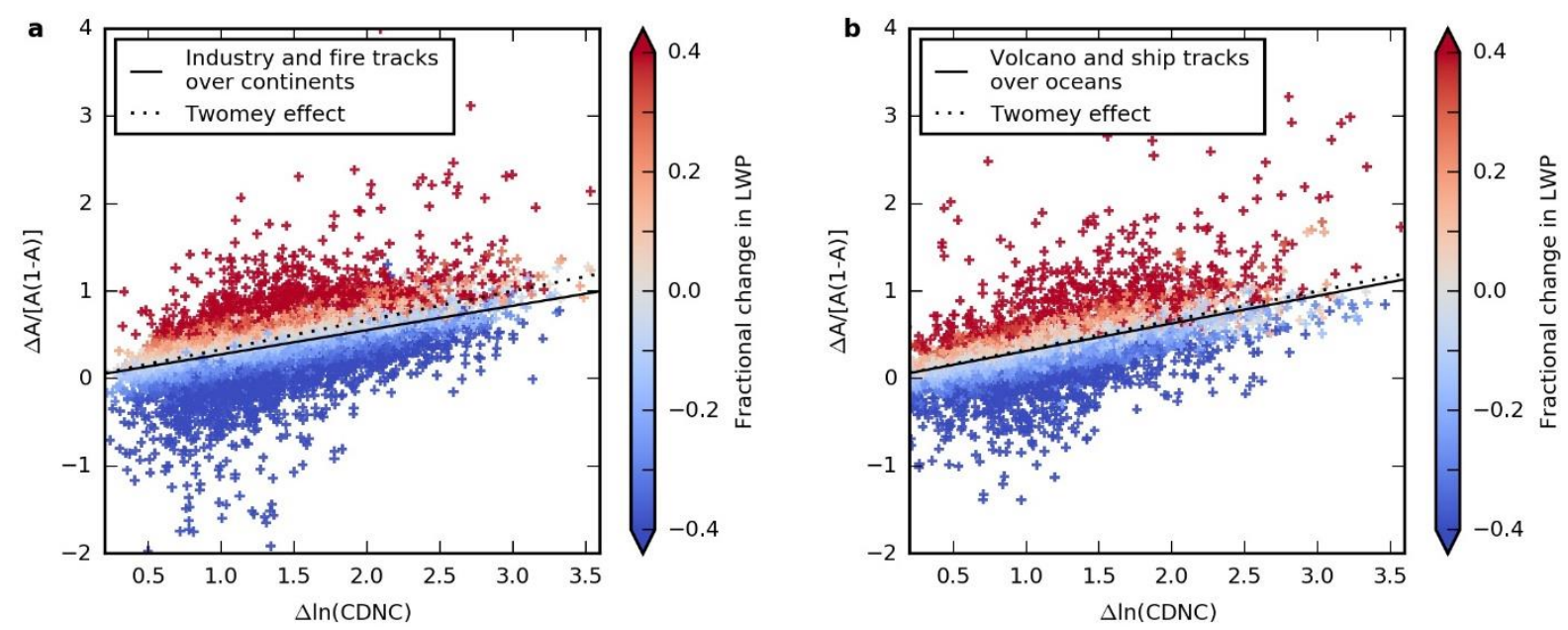

\section{Extended Data Fig. 6: Cloud albedo (A) susceptibility to cloud droplet number concentration (CDNC) perturbation in continental and ocean-based stratiform clouds. The} solid black line (forced through the origin) shows a least squares fit to cloud albedo susceptibility in pollution tracks. The dashed black line shows the slope of $1 / 3$ expected just from the Twomey effect assuming constant liquid water path (LWP). Fractional changes in LWP for individual tracks are given in colour. a) For land-based industry and fire tracks the slope of the fitted solid black line is 0.27 , implying that the relative increase in cloud albedo is less than expected solely from the Twomey effect. b) For ocean-based volcano and ship tracks the slope of the fitted solid black line is 0.32 , implying that the relative increase in cloud albedo is very similar to the one expected solely from the Twomey effect. 
Extended Data Table 1: Comparisons between polluted and unpolluted cloud properties

for various types of pollution tracks. Average relative differences between in track and nearby unpolluted cloud properties are given for liquid water path (LWP), cloud droplet effective radius $\left(\mathrm{R}_{\mathrm{e}}\right)$, cloud optical depth (COD) and cloud droplet number concentration (CDNC). The means of the properties are given together with the standard deviations in the parentheses. St refers to stratiform clouds and $\mathrm{Cu}$ to trade-wind cumulus clouds.

\begin{tabular}{|c|c|c|c|c|}
\hline Property & Type of track & Unpolluted area & Polluted area & Relative difference [\%] \\
\hline \multirow[t]{6}{*}{ LWP $\left[g / m^{2}\right]$} & Industry St land & $141.6(80.9)$ & $125.4(79.8)$ & $-8.1(32.7)$ \\
\hline & Large industry St land & $190.2(159.0)$ & $131.3(92.8)$ & $-14.4(52.1)$ \\
\hline & Fires St land & $136.9(70.2)$ & $127.2(78.4)$ & $-6.7(25.9)$ \\
\hline & Volcano St ocean & $142.1(107.2)$ & $121.1(93.9)$ & $-3.9(48.0)$ \\
\hline & Volcano Cu ocean & $163.5(129.4)$ & $133.1(79.5)$ & $+14.2(86.8)$ \\
\hline & Ship St ocean & $89.6(46.8)$ & $89.9(57.8)$ & $+9.1(80.0)$ \\
\hline \multirow[t]{6}{*}{$R_{e}[\mu \mathrm{m}]$} & Industry St land & $14.2(3.7)$ & $8.5(1.9)$ & $-38.8(10.3)$ \\
\hline & Large industry St land & $11.6(2.4)$ & $7.2(1.3)$ & $-37.2(8.9)$ \\
\hline & Fires St land & $13.9(4.4)$ & $8.8(2.7)$ & $-35.5(9.9)$ \\
\hline & Volcano St ocean & $12.8(3.3)$ & $7.7(1.7)$ & $-38.3(10.1)$ \\
\hline & Volcano Cu ocean & $17.0(3.8)$ & $7.3(2.3)$ & $-56.1(11.5)$ \\
\hline & Ship St ocean & $15.9(4.3)$ & $11.3(2.9)$ & $-28.4(9.3)$ \\
\hline \multirow[t]{6}{*}{ COD } & Industry St land & $15.8(8.4)$ & $23.0(12.7)$ & $+56.8(62.8)$ \\
\hline & Large industry St land & $26.0(20.2)$ & $28.9(18.0)$ & $+40.1(90.3)$ \\
\hline & Fires St land & $16.3(8.6)$ & $23.2(13.1)$ & $+49.6(46.7)$ \\
\hline & Volcano St ocean & $17.7(12.6)$ & $25.1(18.1)$ & $+66.0(95.6)$ \\
\hline & Volcano Cu ocean & $15.2(11.6)$ & $30.5(17.9)$ & +163.3 (176.2) \\
\hline & Ship St ocean & $9.1(4.8)$ & $12.2(6.3)$ & $+58.8(130.7)$ \\
\hline \multirow[t]{6}{*}{$\operatorname{CDNC}\left[1 / \mathrm{cm}^{3}\right]$} & Industry St land & $82.9(53.7)$ & $317.6(171.8)$ & $+381.7(337.6)$ \\
\hline & Large industry St land & $152.0(87.1)$ & $511.2(250.2)$ & $+294.4(240.5)$ \\
\hline & Fires St land & $107.8(87.2)$ & 346.1 (243.9) & $+294.0(249.2)$ \\
\hline & Volcano St ocean & $106.7(62.1)$ & 405.4 (227.9) & $+394.8(435.7)$ \\
\hline & Volcano Cu ocean & $61.9(54.5)$ & $610.7(440.9)$ & +1197.1(1048.4) \\
\hline & Ship St ocean & $49.9(39.3)$ & $112.6(71.9)$ & +186.5 (216.9) \\
\hline
\end{tabular}


Extended Data Table 2: Average characteristics of various types of tracks. Numbers of sampled pollution track segments together with median cloud top heights and relative humidity above clouds in track regions and average liquid water path (LWP) sensitivity to cloud droplet number concentration $(C D N C) \Delta \operatorname{lnLWP} / \Delta \ln C D N C$. St refers to stratiform clouds and $\mathrm{Cu}$ to trade-wind cumulus clouds. For $\Delta \operatorname{lnLWP} / \Delta \operatorname{lnCDNC}$ standard error is given in the parentheses.

\begin{tabular}{ccccc}
\hline Type of track & $\begin{array}{c}\text { Number of track } \\
\text { observations }\end{array}$ & Cloud top height [m] & Relative humidity [\%] & $\Delta$ InLWP/DInCDNC \\
\hline Industry St land & 6478 & 2259 & 42.6 & $-0.071(0.003)$ \\
Large industry St land & 984 & 2862 & 34.2 & $-0.215(0.018)$ \\
Fires St land & 1389 & 2532 & 46.5 & $-0.088(0.006)$ \\
Volcano St ocean & 2521 & 1311 & 39.7 & $-0.107(0.007)$ \\
Volcano Cu ocean & 831 & 1471 & 76.1 & $+0.051(0.012)$ \\
Ship St ocean & 793 & 721 & 26.6 & $-0.021(0.013)$ \\
\hline
\end{tabular}


Extended Data Table 3: Approximate sulphur dioxide $\left(\mathrm{SO}_{2}\right)$ emission rates [kt/year] for various emission sources.

\begin{tabular}{cc}
\hline Emission source & $\begin{array}{c}\text { Approximate } \mathrm{SO}_{2} \\
\text { emission rate [kt/year] }\end{array}$ \\
\hline $\begin{array}{c}\text { Ambrym volcano } \\
\text { South Sandwich Islands and Kuril } \\
\text { Islands volcanoes }\end{array}$ & $\sim 3500^{51}$ \\
\hline $\begin{array}{c}\text { Smelters, oil refineries, power } \\
\text { plants } \\
\text { Ships }\end{array}$ & $\sim 50-250^{51}$ \\
\hline
\end{tabular}


Extended Data Table 4: Liquid water path (LWP) sensitivity to cloud droplet number concentration (CDNC) perturbation depending on cloud droplet effective radius ( $\left.R_{\mathrm{e}}\right)$. Average $\Delta \operatorname{lnLWP} / \triangle \operatorname{lnCDNC}$ is given for each $\mathrm{R}_{\mathrm{e}}$ interval over ocean and land together with standard error in the parentheses.

\begin{tabular}{|c|c|c|}
\hline$R_{e}$ interval [ $\left.\mu \mathrm{m}\right]$ & $\begin{array}{l}\Delta \operatorname{lnLWPI\Delta InCDNC} \\
\text { volcano and ship } \\
\text { tracks over ocean }\end{array}$ & $\begin{array}{c}\Delta \operatorname{lnLWPI} / \mathrm{InCDNC} \\
\text { industry and fire tracks } \\
\text { over land }\end{array}$ \\
\hline$R_{e}<10.5$ & $-0.115(0.013)$ & $-0.124(0.014)$ \\
\hline $10.5<=R_{e}<13.5$ & $-0.140(0.012)$ & $-0.145(0.005)$ \\
\hline $13.5<=R_{e}<16.5$ & $-0.068(0.015)$ & $-0.104(0.006)$ \\
\hline $16.5<=R_{e}<19.5$ & $-0.004(0.017)$ & $-0.043(0.006)$ \\
\hline $19.5<=R_{e}<22.5$ & $+0.052(0.033)$ & $-0.035(0.009)$ \\
\hline$R_{e}>=22.5$ & $+0.106(0.035)$ & $-0.008(0.017)$ \\
\hline
\end{tabular}

